Article

\title{
Application of Urban Scale Energy Modelling and Multi-Objective Optimization Techniques for Building Energy Renovation at District Scale
}

\author{
Fahad Haneef ${ }^{1}$, Giovanni Pernigotto ${ }^{1, *} \mathbb{B}$, Andrea Gasparella ${ }^{1}$ and Jérôme Henri Kämpf ${ }^{2} \mathbb{D}$ \\ 1 Faculty of Science and Technology, Free University of Bozen-Bolzano, 39100 Bolzano, Italy; \\ fahad.haneef@natec.unibz.it (F.H.); andrea.gasparella@unibz.it (A.G.) \\ 2 Energy Informatics Group, Idiap Research Institute, 1920 Martigny, Switzerland; jerome.kaempf@idiap.ch \\ * Correspondence: giovanni.pernigotto@unibz.it; Tel.: +39-0471017632
}

\section{check for} updates

Citation: Haneef, F.; Pernigotto, G.; Gasparella, A.; Kämpf, J.H. Application of Urban Scale Energy Modelling and Multi-Objective Optimization Techniques for Building Energy Renovation at District Scale. Sustainability 2021, 13, 11554. https:// doi.org/10.3390/su132011554

Academic Editors: Agnese Salvati, Gianpiero Evola, Massimo Palme and Giacomo Chiesa

Received: 29 August 2021

Accepted: 15 October 2021

Published: 19 October 2021

Publisher's Note: MDPI stays neutral with regard to jurisdictional claims in published maps and institutional affiliations.

Copyright: (c) 2021 by the authors. Licensee MDPI, Basel, Switzerland. This article is an open access article distributed under the terms and conditions of the Creative Commons Attribution (CC BY) license (https:// creativecommons.org/licenses/by/ $4.0 /)$.

\begin{abstract}
Nearly-zero energy buildings are now a standard for new constructions. However, the real challenge for a decarbonized society relies in the renovation of the existing building stock, selecting energy efficiency measures considering not only the energy performance but also the economic and sustainability ones. Even if the literature is full of examples coupling building energy simulation with multi-objective optimization for the identification of the best measures, the adoption of such approaches is still limited for district and urban scale simulation, often because of lack of complete data inputs and high computational requirements. In this research, a new methodology is proposed, combining the detailed geometric characterization of urban simulation tools with the simplification provided by "building archetype" modeling, in order to ensure the development of robust models for the multi-objective optimization of retrofit interventions at district scale. Using CitySim as an urban scale energy modeling tool, a residential district built in the 1990s in Bolzano, Italy, was studied. Different sets of renovation measures for the building envelope and three objectives -i.e., energy, economic and sustainability performances, were compared. Despite energy savings from 29 to $46 \%$, energy efficiency measures applied just to the building envelope were found insufficient to meet the carbon neutrality goals without interventions to the system, in particular considering mechanical ventilation with heat recovery. Furthermore, public subsidization has been revealed to be necessary, since none of the proposed measures is able to pay back the initial investment for this case study.
\end{abstract}

Keywords: urban simulation; urban scale energy modeling; CitySim; building energy retrofitting; multi-objective optimization; building archetypes

\section{Introduction \\ 1.1. Building Energy Efficiency in the European Framework for 2050 Decarbonization}

By 2050, the world population will reach 9.7 bn [1], leading to nearly $70 \%$ more households from 1.9 bn in 2010 to 3.2 bn in 2050 [2]. As a result, cities will continue to expand, leading to a drastic climb in building energy needs. Consequently, action is needed now to hit the net zero energy targets by 2050. In that respect, communities should lead the way and cities should unlock their enormous energy saving potential, especially through building retrofit interventions [3,4]. Moreover, the transition from the current position to more sustainable, low carbon communities can be achieved following strategies to (i) switch from conventional to renewable energy sources, and (ii) reduce urban energy use [5]. In 2012, the 2012/27/EU Energy Efficiency Directive EED [6] added significant new elements to define a pathway to a "highly efficient and decarbonized building stock by 2050". A few years later, the recast of the Energy Performance of Buildings Directive (EPBD recast), i.e., the new Directive 2018/844/EU [7], defined policies and regulation actions for the Member States to make the transition from the current energy intensive building stock to nearly zero energy buildings. In particular, the Member States are now required to: 
“Establish a long-term strategy beyond 2020 for mobilizing investments in the renovation of residential and commercial buildings with a view to improving the energy performance of the building stock. That strategy should address cost-effective deep renovations which lead to a refurbishment that reduces both the delivered and the final energy consumption of a building by a significant percentage compared with the prerenovation levels leading to a very high energy performance" [6].

At the moment, the building sector is the biggest energy consumer in Europe, accounting for around $40 \%$ of EU energy demand and almost $36 \%$ of $\mathrm{CO}_{2}$ emissions in the EU [8]. The analysis of the Buildings Performance Institute Europe (BPIE) on the available Energy Performance Certificate label data, introduced by the EPBD, found that only $3 \%$ of the EU existing building stock qualifies as A-label and roughly $97 \%$ is energy inefficient [9]. The BPIE report also concluded that with the current $1-1.2 \%$ renovation rate [10], it will take almost a century to decarbonize the whole building stock. Moreover, it is estimated that $90 \%$ of today's buildings will still exist in $2050,75 \%$ of them from a time with no or very poor energy performance requirements [11]. Solutions available today are to implement national renovation strategies which include bringing the renovation rate to $3 \%$ per year and reducing building energy demand in the EU by $80 \%$ by 2050 , with the remaining $20 \%$ supplied by renewable sources [12].

In order to achieve the long-term goals of a decarbonized building stock, a life-cycle approach should be adopted, accounting also for the impact of embodied carbon emissions in building materials, as well as in construction- and demolition-phase activities. In this framework, according to the Architecture 2030 consortium, embodied carbon in buildings must be reduced by $65 \%$ by 2030 and to zero by 2040 [13]. Concerning the decarbonization of the building sector, the literature lists measures for energy efficiency aimed at addressing five challenges:

1. Improving energy efficiency $[14,15]$;

2. Increasing renewable energy share [15];

3. Fixing the "performance gap" [16,17];

4. Accelerating the building renovation rate [12,18];

5. Assessing "embodied energy" [19].

Although some of these strategies can be applied to individual buildings, tackling the energy efficiency issues at the neighborhood or urban scale allows for results unattainable differently [20], such as the design of smart districts or building integrated energy communities [21]. A recent study by Salom and Pascual [22] reported that a step by step renovation is still dominating the market, and suggested that building retrofit interventions applied at a district scale can increase the current renovation rate from $1 \%$ to $3 \%$ or higher. Moreover, the energy efficiency measures implemented have to be carefully selected to also be effective in future scenarios, including the impact of climate change [23]. However, this task can be complex to fulfill, especially for those locations, such as many Mediterranean ones, already characterized by both significant heating and cooling demands. In this respect, multi-objective optimization has been widely used for finding the optimal solutions for retrofitting and cost-effective energy efficiency measures in the building sector, both in individual and in small groups of buildings [24-28].

\subsection{Overview of Urban Building Energy Modeling}

During the last decades, building performance simulation tools have been developed for complex thermal modeling and energy behavior of individual buildings [29]. Although building energy models (BEM) can be expanded from a single building to sets of buildings, the high amount of information and computational time required make them an unfeasible choice [23]. Over the past few years, there have been more and more efforts towards the development of BEM capable of assessing various energy and emission-related interventions on an urban scale [30-32]. Such models are then further categorized based on their modeling approach, number of inputs required, temporal and spatial resolutions [33]. Reinhart and Cerezo Davila [23] termed it as "Urban Building Energy Modeling" (UBEM), which is 
a part of the much broader field of "urban microsimulation" [34]. Swan and Ugursal [35] proposed two basic groups of urban building energy modeling methods, "Top-Down" and "Bottom-Up" models:

- Top-down models. In these methods, the aggregated energy demand of an entire region or country is calculated by means of a black box approach with no correlation whatsoever to the end users $[33,35]$. Such models heavily rely on historical data series-i.e., energy consumption, fuel prices, income data, etc., also often used as indicators in macroeconomic or socio-econometric studies. Because of this and due to the lack of technological details, top-down urban energy models are strongly limited for accurately addressing the potential impact of interventions at the small scale of a district or individual building [33,35].

- Bottom-up models. In contrast to top-down models, this approach not only simulates the energy consumption of individual or groups of buildings but also allows for a distinction to be made between the different end uses (i.e., heating, cooling, lighting, etc.) to help identify areas of improvement [23]. Bottom-up models can be based on either statistical methods or engineering techniques (also known as physical methods).

In their review on existing urban energy modeling tools, Sola et al. [36] reported that most of literature focuses on single-purpose UBEM tools, often dedicated just to the estimation of the thermal energy demand of the building stock. Moreover, those authors underlined the need for multi-domain tools, i.e., Urban Scale Energy Modeling tools (USEM). Sola et al. [36] classified the available tools according to UBEM and USEM categories as follows:

- Urban building energy modeling tools (UBEM): BEM-TEB [37], CHREM [38], CityBES [39], SimStadt [40], TEASER [41], UMI [42].

- Urban scale energy modeling tools (USEM): the model by Best et al. [43], City Energy Analyst CEA [44], CitySim [45], HUES [46], IDEAS [47], LakeSIM [48], MESCOS [49], SynCity [50], URBANopt [51], USEM platform with BCVTB [52], USEM platform in UMEM project [53].

Modeling on an urban scale is a difficult challenge, owing to the complexities of urban environment, data scarcity, computational time, model generation, etc. [54]. Former research efforts tried to address this challenge in various ways. For instance, considering that the input of geometrical and thermo-physical building features can take about a third of the whole modeling effort in UBEM [55], Carnieletto et al. [56] recommended using archetype approaches. Simplified physical modeling routines have also been given more and more attention, as they offer a good trade-off between simplicity, number of input parameters and required computing efforts $[57,58]$. Finally, computational efficiency can be achieved by obtaining geometric and physical characteristic data directly from Geographic Information Systems (GIS) and CityGML [59].

As observed above, effective energy policies require the targeting of interventions at district or city scale, optimizing the energy and economic performance of the whole urban energy system, and allowing, in such a way, the construction of new smart grids interconnecting several groups of buildings to be promoted. Although the use of multi-objective optimization in the domain of energy retrofitting for individual or small groups of buildings has been widely discussed in the literature, the application of district scale retrofitting, encompassing not only energy and economic goals but also environmental sustainability aspects, are less frequent. Indeed, UBEM and USEM coupled with multi-objective optimization have been addressed mainly towards the optimal design and operation of distributed urban energy systems [60-62] and new zero energy districts [63,64], considering, for instance, optimized building shape [65], building geometry and size of energy systems [66], and urban layout $[67,68]$. 


\subsection{Aims of This Research}

As described in the previous sections, addressing building energy renovation at multibuilding and district scale seems to be a requirement, on one hand, to comply with the medium and long-term EU targets and, on the other hand, to put in the basis for the transformation of current neighborhoods into interconnected smart districts. To achieve this goal, the most common approach in the literature couples multi-objective optimization with reference buildings, in order to (a) select the most effective energy efficiency measures and (b) to scale up the results in terms of potential savings at regional or national level. Although this methodology can be very effective for defining an energy policy $[69,70]$, it has limitations when the focus is put on real districts, which, especially in many Mediterranean countries such as Italy, are composed of a variety of buildings of different shapes, features and usages, which can be hardly represented by a small set of reference buildings defined initially from national or regional building stocks. Furthermore, considering the district as a whole, whose performance is to be optimized, interactions among buildings have to be taken into consideration. For instance, from the building-fabric point of view, buildings in a district are characterized by adjacencies, mutual solar radiation reflection and shading, and longwave radiation exchanges, which can significantly alter the boundary conditions with respect to a single reference building [71-73] and affect both heating and cooling energy performance. This is even more critical when different buildings are connected to a network or to small local generation systems serving part of or the whole district, and the climate conditions, as in many Mediterranean areas, are characterized by large seasonal variability, implying the need for systems able to cope with both hot summer and cold winter conditions.

Although the detailed modeling of actual districts with UBEM or USEM tools could be the most accurate solution, it is often difficult to apply, due to lack of complete data. Indeed, while the geometry of districts is nowadays available for several municipalities, even if without standardization [74], and the type and capacity of the heating systems installed in buildings can sometimes be retrieved from energy supply companies, the features of the building envelope and of other HVAC systems (e.g., the cooling system) are often just partially known. In this context, the adoption of building archetypes can be a good solution to overcome this issue, allowing district models to be developed to couple with multi-objective optimization algorithms.

In this framework, this research aims to propose a methodology combining some strong points of $U B E M$ and USEM tools, such as the ability to ensure a detailed geometry characterization and to simulate some complex microclimatic interactions among buildings, with the simplifications provided by "building archetype" modeling, which can allow some obstacles, that occur through the lack of exhaustive information about the features of each building envelope and HVAC system, to be overcome. The proposed approach integrates with traditional multi-objective optimization techniques in order to select the best energy efficiency measures for design interventions at the district scale. Specifically, optimizations are driven by the performance of each group of buildings characterized by the same building archetype.

The methodology presented in this research is applied as an example to a residential neighborhood in the city of Bolzano, Italy, served by the local district heating network. Considering the peculiarities of the case study, with all the buildings with the same HVAC solution (i.e., the district heating), the selected archetypes address just the building envelope and can be referred to as "building envelope archetypes". In the case study analysis, the selection of the best energy efficiency measures is performed by considering three different goals to optimize, i.e., the energy, the economic and the environmental performances. Furthermore, in consideration of the long-term goals, a 2050 future climate is adopted instead of typical weather data. 


\section{Methodology}

As already mentioned in the introduction, the goal of the proposed methodology is to combine the ability to accurately represent the geometry of a district through some UBEM/USEM tools with the simplification of inputs brought by the adoption of building archetypes, ensuring an easier application of the selection of energy efficiency measures EEMs for building renovation through multi-objective optimization techniques. The methodology is not developed for a specific UBEM/USEM tool and can be applied with different urban simulation codes. Nevertheless, it is recommended to select a tool which has already been validated, either against experimental data [75] or in agreement with technical standards developed for $B E M$ validation [76], and proved capable of giving a good level of output accuracy.

The main three steps of the methodology can be summarized as follows:

1. Input data collection and processing. The first step is dedicated to the collection of all the inputs required to prepare an urban simulation model, which are (a) the geometry of the district and (b) the characteristics of the building envelopes and of the HVAC systems.

a. Urban geometry. The geometry is meant to be kept as accurate as possible, distinguishing the shapes and features of each building in the considered district. As mentioned before, Geographical Information Systems (GIS) can provide at least the urban layout for many municipalities, which can be integrated in the development phase with in situ inspections and other sources of data (e.g., orthographic pictures, mapping platforms, etc.). The geometrical model should be prepared taking into account just those features compatible with the chosen UBEM/USEM tool, neglecting unnecessary details. For instance, if the chosen code allows only for a 2.5D approach to model the geometry, or if just the urban layout is available, pitched roofs cannot be modeled.

b. Building archetypes. Detailed and complete data regarding the buildings' fabric and HVAC systems are usually available only for a fraction of the existing buildings in a neighborhood. The best sources for collection of the required information are generally the energy performance certificates, EPCs, which can be acquired from Government Energy Agencies and local public authorities. The sample of EPCs can be processed by means of data-mining techniques, such as $k$-means or $k$-medoids clustering techniques $[70,77,78]$, in order to identify the building archetypes, each one representative for a given cluster of buildings in the district. It is worth noting that the proposed type of clustering does not impose continuity or adjacency constraints and just focuses on the building system features.

Those buildings without an EPC can be associated to the cluster represented by an archetype with similar important features, such as the year of construction (or the year of first renovation intervention), the adopted construction technology, the type of usage, and the installed HVAC system. As mentioned before, in particular cases, for instance, when the neighborhood is entirely served by a district heating or cooling network, the focus can be put only on the building envelope, identifying in such a way the so-called "building envelope archetypes".

In this phase, the characteristics and the accuracy of the collected inputs have to be taken carefully under consideration to address the next development of the urban simulation model. In this respect, the available inputs can affect the target use and potential of the model, having an impact on the level of representativeness of the simulated outputs. For example, if detailed information about the HVAC system regulation and dynamic interaction of the occupancy with the building system is unknown, hourly profiles of energy demand will be affected by a high level of uncertainty. Although the methodologies for model calibration can mitigate this kind 
of issue, the user should understand in this first step which level of detail is actually achievable, as well as necessary, in consideration of the building renovation goals.

2. Preparation, calibration and validation of the urban simulation model. At this stage, all the inputs necessary for preparing an urban simulation model should be available. Consequently, the new goal is to prepare a model and assess its ability to deliver representative results.

To do so, it is recommended to start comparing the energy consumption of each cluster of buildings in the district, simulated using actual meteorological years $A M Y s$, with the recorded historical data series. Considering both time-discretization of the recordings typically available and the state-of-the-art accuracy of the results provided by urban simulation codes [21,79], annual energy consumptions can be a suitable solution for this preliminary step. If the necessary inputs are known with a good level of accuracy and recordings with short-time discretization are available, additional comparisons can be performed, also allowing the assessment of the model's capabilities in predicting short-term energy demand.

In the case of large discrepancies, the calibration and validation of inputs uncertain or alleged to be different from those found in the EPCs, e.g., infiltration and ventilation rates, temperature setpoints and HVAC system efficiencies, should be performed, for example, in agreement with the prescriptions reported by ASHRAE Guideline 14 [80] and IPMVP Guideline [81]. Specifically, acceptable tolerances for calibration and validation should be chosen, depending on the time discretization of the available data recordings. Nevertheless, it should also be remembered that urban simulations require a large amount of input data and some techniques traditionally adopted for $B E M$ calibration can be inappropriate for UBEM/USEM applications [76].

3. Definition of available energy efficiency measures and objective functions for multi-objective optimization. After the model is validated, it is possible to proceed with the selection of the energy efficiency measures EEMs by means of multi-objective optimization.

In this last stage, objective functions and optimization algorithms have first to be chosen, together with the sets of EEMs. Several alternative algorithms are present in the literature and the selection should be based on the efficiency and accuracy, accounting also for the features of the neighborhood under analysis, the considered objective functions, the selected EEMs and the available computational resources. Taking into account the differences between the clusters of buildings, each one represented by its own building archetype, a specific set of EEMs can be defined for each group. Once all inputs and parameters are set, optimization can be run using a typical or modified reference year as the weather file, depending on the goal of the analysis.

The space of solutions is composed by all possible combinations of $n$ sets of EEMs, with each set applied to one of the $k$ clusters of buildings in the modeled neighborhood. At each iteration of the optimization algorithm, a solution vector is evaluated, calculating the values of the objective functions first for each cluster of buildings and then, by addition, for the whole district. Depending on the chosen objective functions and optimization algorithm, the final output can be a Pareto front, including solutions which the policy maker can choose according to the objective for prioritization (e.g., energy efficiency, economic result, etc.).

\section{Case Study}

This section presents the analyzed case study neighborhood, the details of the adopted urban simulation tool, and the implementation of the multi-objective optimization scenarios.

\subsection{Input Data Collection and Processing for the Chosen Case Study}

The case study investigated in this research belongs to the city of Bolzano $\left(46^{\circ} \mathrm{N}\right.$, $\left.11^{\circ} \mathrm{E}\right)$, Northern Italy, in a heating dominated climate. In detail, the selected urban area (Figure 1) is located in the western and more recent part of the city and is composed 
only of residential multi-family houses-95 dwellings built during the period 1990-1995, using similar construction technologies (i.e., concrete and clay-block components), and occupying a floor area of more than $20,000 \mathrm{~m}^{2}$. This district was specifically selected because its buildings are already connected to each other by means of the local district heating network serving this part of the city. Interventions applied to these buildings have not only the advantage of decreasing the energy consumption for space heating but also the potential reduction of the hot water temperature of the network, provided that a sufficient degree of uniformity is achieved for the whole district [82]. Consequently, the improvement of the case study building's energy performance could be the first step towards its renovation into a smart district.
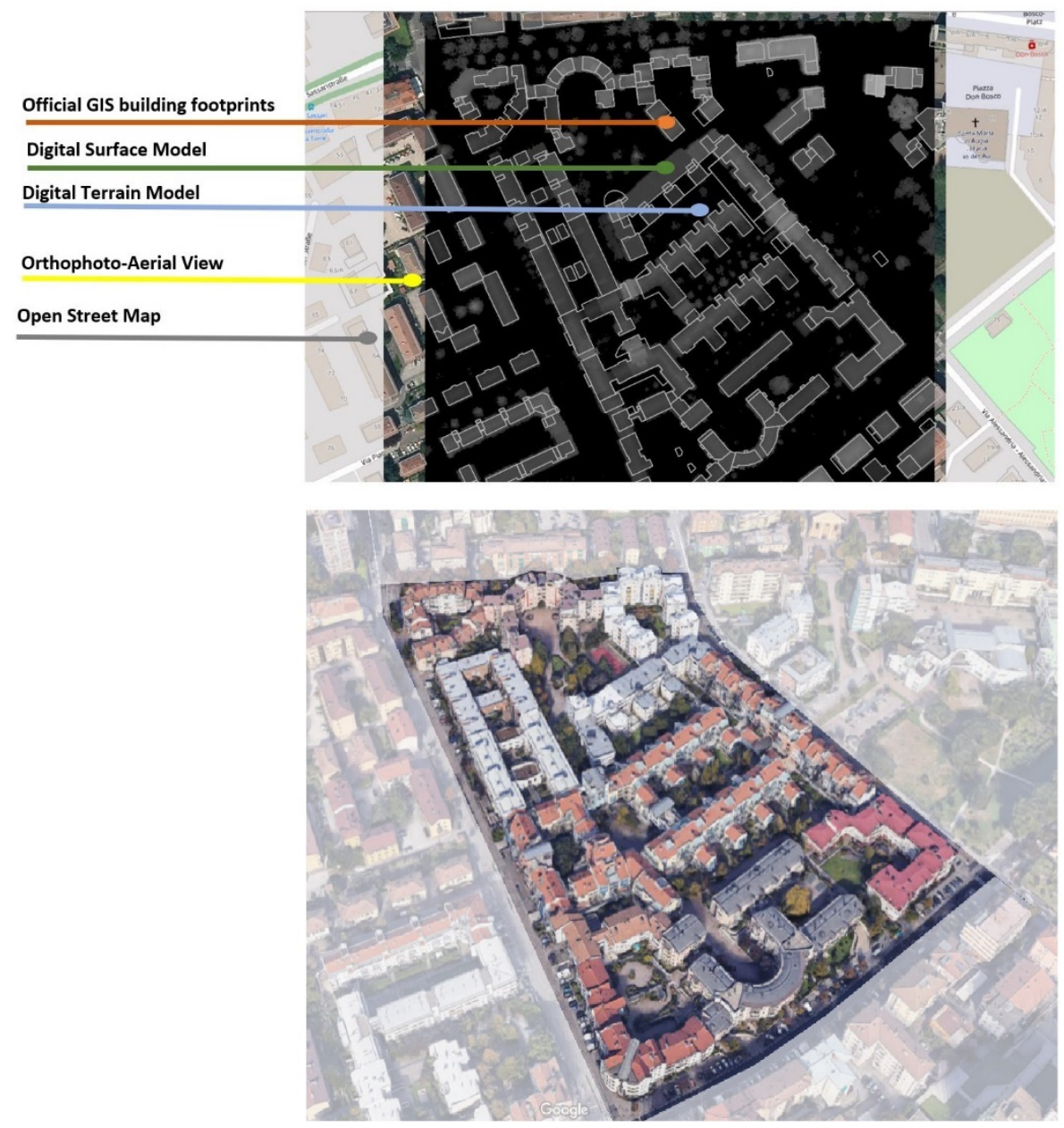

Figure 1. GIS data incorporated in the present study visualized in a GIS platform (top) and a 3D map based on Google Maps ((bottom), Dati Cartografici @2021 Google).

In order to prepare the geometrical model of the selected district, the official Geographic Information Systems (GIS) of the city of Bolzano was consulted (http: / geocatalogo. retecivica.bz.it/geokatalog, accessed on 10 February 2020). Since only building footprints were available, building heights were estimated by calculating with the software QGIS the difference between the city orthographic data of the digital surface model (DSM) and the digital terrain model (DTM). A standard floor height of $3 \mathrm{~m}$ was assumed for estimating the number of floors for each building. As regards the window-to-floor ratio, a minimum value of $1 / 8$ was assumed in compliance with the current Italian regulations. Results were further verified with Google 3D maps and Open Street Maps and, where feasible, with local surveys.

Considering that all buildings in the case study are supplied by the local district heating network, the focus was put only on the building envelope to identify clusters and 
archetypes. From the analysis of the building energy performance certificates provided by the local energy agency, i.e., Klimahaus Agency, three clusters were identified. Clusters 1, 2 and 3 include, respectively, $61 \%, 15 \%$ and $24 \%$ of the conditioned floor area in the case study district. Each cluster is represented by the building envelope archetypes described in Tables 1 and 2. The three archetypes are differentiated mainly by roof and ground floor insulation and are all characterized by the same type of windows (i.e., air-filled double glazed windows).

Table 1. Composition of the main building components for the three building envelope archetypes (layers indicated from the internal to the external surface).

\begin{tabular}{|c|c|c|c|c|c|c|}
\hline \multicolumn{7}{|c|}{ Archetype 1} \\
\hline & & Layer & $\begin{array}{l}\text { Thickness } \\
{[\mathrm{m}]}\end{array}$ & $\begin{array}{l}\text { Thermal Conductivity } \\
{\left[\mathrm{W} \mathrm{m}^{-1} \mathrm{~K}^{-1}\right]}\end{array}$ & $\begin{array}{l}\text { Density } \\
{\left[\mathrm{kg} \mathrm{m}^{-3}\right]}\end{array}$ & $\begin{array}{c}\text { Specific Heat Capacity } \\
{\left[\mathrm{J} \mathrm{kg}^{-1} \mathrm{~K}^{-1}\right]}\end{array}$ \\
\hline \multirow{3}{*}{ Walls } & 1 & Cement plaster & 0.020 & 1.00 & 2000 & 1130 \\
\hline & 2 & Clay block & 0.380 & 0.36 & 850 & 880 \\
\hline & 3 & Thermal insulating plaster & 0.040 & 0.10 & 300 & 1200 \\
\hline \multirow{5}{*}{ Roof } & 1 & Plasterboard & 0.010 & 0.21 & 900 & 1050 \\
\hline & 2 & Insulating layer & 0.100 & 0.04 & 38 & 1450 \\
\hline & 3 & Concrete and clay block slab & 0.240 & 0.80 & 1600 & 1110 \\
\hline & 4 & Screed & 0.120 & 0.60 & 1500 & 1110 \\
\hline & 5 & Tiles & 0.010 & 1.00 & 1800 & 900 \\
\hline \multirow{5}{*}{$\begin{array}{l}\text { Ground } \\
\text { Floor }\end{array}$} & 1 & Timber flooring & 0.015 & 0.13 & 600 & 1610 \\
\hline & 2 & Concrete underlay & 0.065 & 0.30 & 800 & 1450 \\
\hline & 3 & Light concrete & 0.080 & 0.16 & 550 & 1270 \\
\hline & 4 & Slab & 0.250 & 0.55 & 1200 & 1130 \\
\hline & 5 & Insulating layer & 0.040 & 0.04 & 38 & 1450 \\
\hline \multicolumn{7}{|c|}{ Archetype 2} \\
\hline & & Layer & $\begin{array}{l}\text { Thickness } \\
{[\mathrm{m}]}\end{array}$ & $\begin{array}{l}\text { Thermal Conductivity } \\
\qquad\left[\mathrm{W} \mathrm{m}{ }^{-1} \mathrm{~K}^{-1}\right]\end{array}$ & $\begin{array}{l}\text { Density } \\
{\left[\mathrm{kg} \mathrm{m}^{-3}\right]}\end{array}$ & $\begin{array}{l}\text { Specific Heat Capacity } \\
{\left[\mathrm{J} \mathrm{kg}^{-1} \mathrm{~K}^{-1}\right]}\end{array}$ \\
\hline \multirow{3}{*}{ Walls } & 1 & Lime-cement plaster & 0.010 & 0.80 & 1800 & 1130 \\
\hline & 2 & Clay block & 0.380 & 0.36 & 850 & 880 \\
\hline & 3 & Thermal insulating plaster & 0.030 & 0.10 & 300 & 1200 \\
\hline \multirow{4}{*}{$\begin{array}{c}\text { Roof } \\
\text { (unventilated) }\end{array}$} & 1 & Fiber cement boards & 0.015 & 0.60 & 2000 & 1050 \\
\hline & 2 & Mineral wool & 0.100 & 0.04 & 30 & 1030 \\
\hline & 3 & $\begin{array}{l}\text { Air gap + timber beams } \\
\left(\mathrm{R}=1.2 \mathrm{~m}^{2} \mathrm{~K} \mathrm{~W}^{-1}\right)\end{array}$ & 0.130 & & & \\
\hline & 4 & Roof planks & 0.028 & 0.13 & 495 & 2000 \\
\hline \multirow{5}{*}{$\begin{array}{l}\text { Ground } \\
\text { Floor }\end{array}$} & 1 & Ceramic tiles & 0.010 & 1.30 & 2300 & 840 \\
\hline & 2 & Screed & 0.050 & 0.60 & 1500 & 1110 \\
\hline & 3 & Light concrete & 0.070 & 0.16 & 550 & 1270 \\
\hline & 4 & Slab & 0.200 & 0.55 & 1200 & 1130 \\
\hline & 5 & Foam glass & 0.050 & 0.05 & 120 & 1000 \\
\hline \multicolumn{7}{|c|}{ Archetype 3} \\
\hline & & Layer & $\begin{array}{l}\text { Thickness } \\
{[\mathrm{m}]}\end{array}$ & $\begin{array}{l}\text { Thermal Conductivity } \\
{\left[\mathrm{W} \mathrm{m}^{-1} \mathrm{~K}^{-1}\right]}\end{array}$ & $\begin{array}{l}\text { Density } \\
{\left[\mathrm{kg} \mathrm{m}^{-3}\right]}\end{array}$ & $\begin{array}{c}\text { Specific Heat Capacity } \\
{\left[\mathrm{J} \mathrm{kg}^{-1} \mathrm{~K}^{-1}\right]}\end{array}$ \\
\hline \multirow{3}{*}{ Walls } & 1 & Lime-gypsum plaster & 0.010 & 0.70 & 1300 & 900 \\
\hline & 2 & Clay block & 0.380 & 0.22 & 820 & 930 \\
\hline & 3 & Lime-gypsum plaster & 0.010 & 0.70 & 1300 & 900 \\
\hline \multirow{3}{*}{$\begin{array}{c}\text { Roof } \\
\text { (ventilated) }\end{array}$} & 1 & Lime-gypsum plaster & 0.015 & 0.70 & 1300 & 900 \\
\hline & 2 & Wood boards & 0.020 & 0.13 & 495 & 2000 \\
\hline & 3 & $\begin{array}{l}\text { Mineral wool, ventilated air } \\
\text { gap and covering layers }\end{array}$ & 0.100 & 0.04 & 30 & 1030 \\
\hline \multirow{4}{*}{$\begin{array}{l}\text { Ground } \\
\text { Floor }\end{array}$} & 1 & Timber flooring & 0.010 & 0.13 & 600 & 1610 \\
\hline & 2 & Screed & 0.060 & 0.60 & 1500 & 1110 \\
\hline & 3 & XPS & 0.060 & 0.04 & 38 & 1450 \\
\hline & 4 & Slab & 0.240 & 0.55 & 1200 & 1130 \\
\hline
\end{tabular}


Table 2. Average thermal transmittances of the building components $\left(\mathrm{W} \mathrm{m}^{-2} \mathrm{~K}^{-1}\right)$ for the three building envelope archetypes.

\begin{tabular}{ccccc}
\hline & Wall & Roof & Floor & Windows \\
\hline Archetype 1 & 0.60 & 0.32 & 0.39 & 3.2 \\
Archetype 2 & 0.64 & 0.24 & 0.46 & 3.2 \\
Archetype 3 & 0.52 & 0.35 & 0.43 & 3.2 \\
\hline
\end{tabular}

Other inputs to the model, such as internal gains and occupancy profiles for which detailed data were missing, were set in agreement with the technical standard UNI/TS 11300-1:2014 [83] and EN 16798-1:2019 [84]. More details about the case study, in particular as regards the proposed archetypes, can be found in Haneef et al. [85] and in Battini et al. [86].

\subsection{Preparation, Calibration and Validation of the Urban-Scale Energy Model}

The urban-scale building energy simulation platform selected for this study is CitySim, a C++ based command-line integrated solver initially developed at the Solar Energy and Building Physics Laboratory (LESO-PB) of Ecole Polytechnique Federal de Lausanne (EPFL). CitySim implements a resistor-capacitor-based thermal network model to simulate the energy balance of the built environment, can perform a detailed characterization of the solar radiation available in the urban environment by means of a sky discretization into patches, and allows for the modeling of the HVAC system while considering the interdependent relationship with occupants' presence and behavior [57]. In order to successfully estimate the urban building's energy needs, the software requires as inputs a geometrical model subdivided into different layers-such as walls, roofs, and floorsand incorporating surrounding buildings as shadings, a weather file, an additional file including data on the horizon profile, and the thermo-physical properties of the modeled building stock. CitySim has already been used in several studies in the literature and has also been validated adopting the ANSI/ASHRAE 140 BESTEST cases [87], showing a good level of accuracy.

Figure 2 provides the graphical representation of the case study district as modeled in the GUI CitySim Pro. Since, apart from the 2D footprint and height, no other data were available on the geometrical features of the buildings, a 2.5D model was chosen.

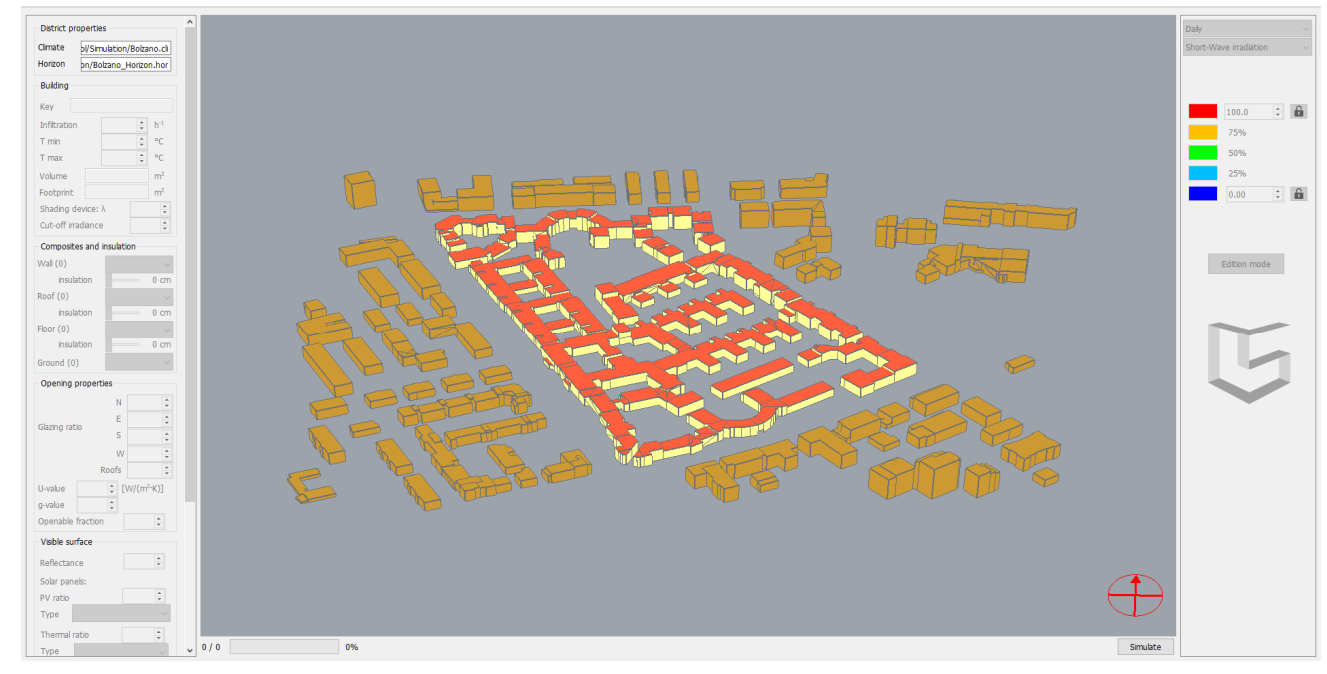

Figure 2. GUI CitySim Pro with the 2.5D model of the case study.

The output of the prepared CitySim model was compared to the 2012-2015 annual consumption data for space heating, finding calibration and validation necessary especially for infiltration and ventilation rates and HVAC system efficiencies. Due to the limited data 
available, the process was performed according to a $k$-fold cross calibration-validation approach, selecting the energy demand of a given year for validation and the remaining ones for calibration, iterating the procedure to cover all possible combinations of groups, and finally assuming as calibrated values those occurring with the highest frequency. A complete validation of the developed model was reported in a previous study [85]. The final uses for space heating in the considered period ranged from 4243 to $4915 \mathrm{MWh}$, with the heating degree-days calculated with respect to a base temperature of $18{ }^{\circ} \mathrm{C}, H D D_{18}$, ranging from 1985 to $2391 \mathrm{~K} \mathrm{~d}$, and the cooling degree-days with respect to the same base temperature, $C D D_{18}$, going from 376 to $661 \mathrm{~K} \mathrm{~d}$. The model output showed a good agreement with the measured values, within a $\pm 5 \%$ deviation from the actual recordings considering the district as a whole, in agreement with the ASHRAE Guideline 14 thresholds for monthly and longer period calibrations.

\subsection{Simulation Scenarios and Multi-Objective Optimization}

With the aim of developing solutions with long-term robustness in a climate change framework, simulations were run with a future weather file. Business as usual (BAU) and multi-objective optimization retrofit scenarios were considered.

Finally, in an attempt to further discuss the energy efficiency measures required to meet the long-term target of $80 \%$ energy demand reduction, the energy optimum found in the multi-objective optimization was also simulated, considering additional efficiency measures involving the mechanical ventilation system.

\subsubsection{Business as Usual Scenario}

In the $B A U$ scenario, a projection of current energy performance of the considered case study was performed according to the 2050 future climate for the city of Bolzano, without considering any intervention on the building stock. In order to quantify the climate change impact, a 2050 weather file was generated with Meteonorm according to the A2 BAU climate change scenario of the emission scenarios report for the period 1961-2100 by the Intergovernmental Panel on Climate Change (IPCC) AR4 [88]. The A2 scenario portrays a high-risk future by excluding any rigorous climate mitigation policies [89]. The developed 2050 weather files shows $H D D_{18}$ equal to $2081 \mathrm{~K} \mathrm{~d}$ and $C D D_{18}$ equal to $686 \mathrm{~K} \mathrm{~d}$, significantly warmer with respect to the period 2012-2015 considered for the model calibration and validation, characterized by average $H D D_{18}=2259 \pm 186 \mathrm{~K} \mathrm{~d}$ and $C D D_{18}=549 \pm 124 \mathrm{~K} \mathrm{~d}$.

\subsubsection{Selection of Energy Efficiency Measures}

Since the specific case study is served by the local district heating network, the energy efficiency measures EEMs were selected only from those improving the energy performance of the building envelope, accounting for typical off-the-shelf interventions, like building insulation and window substitution. In compliance with the minimum requirements established by the Italian Government [90] for the climatic zone where Bolzano is located, i.e., climate zone $\mathrm{E}$ characterized by heating degree-days with respect to a base temperature of $20{ }^{\circ} \mathrm{C}$ ranging from 2101 to $3000 \mathrm{~K} \mathrm{~d}$, the EEMs were selected to provide thermal transmittances lower than $0.26 \mathrm{~W} \mathrm{~m}^{-2} \mathrm{~K}^{-1}, 0.22 \mathrm{~W} \mathrm{~m}^{-2} \mathrm{~K}^{-1}$ and $1.4 \mathrm{~W} \mathrm{~m}^{-2} \mathrm{~K}^{-1}$, respectively, for vertical walls, roofs and windows. EEMs were applied to the whole external building envelope as in a deep renovation, i.e., partial interventions involving just the windows or some opaque elements (a façade or the roof) were not considered.

Three different types of insulating materials were accounted for:

1. Extruded polystyrene (XPS) - with a thermal conductivity $\lambda=0.035 \mathrm{~W} \mathrm{~m}^{-1} \mathrm{~K}^{-1}$, a density $\rho=30 \mathrm{~kg} \mathrm{~m}^{-3}$, and a specific thermal capacity $c=1450 \mathrm{~J} \mathrm{~kg}^{-1} \mathrm{~K}^{-1}$;

2. Mineral wool—with $\lambda=0.038 \mathrm{~W} \mathrm{~m}^{-1} \mathrm{~K}^{-1}, \rho=130 \mathrm{~kg} \mathrm{~m}^{-3}, c=1030 \mathrm{~J} \mathrm{~kg}^{-1} \mathrm{~K}^{-1}$;

3. Cellulose fiber-with $\lambda=0.045 \mathrm{~W} \mathrm{~m}^{-1} \mathrm{~K}^{-1}, \rho=160 \mathrm{~kg} \mathrm{~m}^{-3}, c=2000 \mathrm{~J} \mathrm{~kg}^{-1} \mathrm{~K}^{-1}$.

Insulation material properties were defined according to the technical standard UNI 10351 [91] and the building material database by the local energy agency, i.e., the Klimahaus 
Agency. Two discrete thicknesses of insulation were accounted for-i.e., the minimum thickness in compliance with the law requirements for each considered material (Table 3) and the maximum of $20 \mathrm{~cm}$. Intermediate thicknesses were neglected since the proposed alternatives were judged sufficiently representative to give practical information at district scale.

Table 3. Minimum insulation thicknesses needed to respect the current law requirements for walls and roofs of the different building envelope archetypes.

\begin{tabular}{ccccc}
\hline Type of Insulation & Element & Archetype 1 & Archetype 2 & Archetype 3 \\
\hline \multirow{2}{*}{ XPS } & Wall & $8 \mathrm{~cm}$ & $8 \mathrm{~cm}$ & $7 \mathrm{~cm}$ \\
& Roof & $5 \mathrm{~cm}$ & $2 \mathrm{~cm}$ & $6 \mathrm{~cm}$ \\
\hline \multirow{2}{*}{ Mineral Wool } & Wall & $9 \mathrm{~cm}$ & $9 \mathrm{~cm}$ & $8 \mathrm{~cm}$ \\
& Roof & $6 \mathrm{~cm}$ & $2 \mathrm{~cm}$ & $7 \mathrm{~cm}$ \\
\hline \multirow{2}{*}{ Cellulose Fiber } & Wall & $10 \mathrm{~cm}$ & $11 \mathrm{~cm}$ & $9 \mathrm{~cm}$ \\
& Roof & $7 \mathrm{~cm}$ & $2 \mathrm{~cm}$ & $8 \mathrm{~cm}$ \\
\hline
\end{tabular}

Four types of new windows in compliance with the current law minimum requirements (i.e., a thermal transmittance lower than $1.4 \mathrm{~W} \mathrm{~m}^{-2} \mathrm{~K}^{-1}$ ), were included in the $E E M s$, considering the glazing systems reported in Table 4 and aluminum frames with thermal $\operatorname{break}\left(U_{f r}=1.2 \mathrm{~W} \mathrm{~m}^{-2} \mathrm{~K}^{-1}\right)$.

Table 4. Thermal transmittance $\left(U_{g l}\right)$ and Solar Heat Gain Coefficient $(S H G C)$ of the new glazing systems.

\begin{tabular}{cccc}
\hline & Glazing System & $\boldsymbol{U}_{g l}\left[\mathbf{W} \mathbf{~ m}^{-\mathbf{2}} \mathbf{K}^{-\mathbf{1}}\right]$ & $S H G C[-]$ \\
\hline$D H$ & Double glazing with high SHGC & 1.14 & 0.61 \\
\hline$D L$ & Double glazing with low SHGC & 1.10 & 0.35 \\
\hline$T H$ & Triple glazing with high SHGC & 0.61 & 0.58 \\
\hline$T L$ & Triple glazing with low SHGC & 0.60 & 0.34 \\
\hline
\end{tabular}

The unitary investment $\operatorname{costs} C$ for the insulation layers, also including the installation costs, were estimated starting from the data of the official regional price list of the neighboring Province of Trento. The resulting Equations (1)-(3) were applied to both vertical walls and roofs, as a function of the insulation thickness $s(\mathrm{~m})$. The same costs reported in Pernigotto et al. [92] were used for the new windows and their installation (respectively, DH: 404.33 EUR m ${ }^{-2}$, DL: 439.06 EUR m ${ }^{-2}$, TH: 477.65 EUR m $^{-2}$, TL: 454.49 EUR m $^{-2}$ ).

$$
\begin{gathered}
\mathrm{C}_{\mathrm{XPS}}=112.5 \cdot s+55.6 \mathrm{EUR} \mathrm{m}^{-2}, \\
\mathrm{C}_{\text {mineral_wool }}=213.6 \cdot \mathrm{s}+70.2 \mathrm{EUR} \mathrm{m}^{-2}, \\
\mathrm{C}_{\text {cellulose_fiber }}=363.7 \cdot \mathrm{s}+74.6 \mathrm{EUR} \mathrm{m}^{-2} .
\end{gathered}
$$

The environmental impact of the proposed EEMs was expressed in terms of global warming potential (GWP), i.e., as kilograms of $\mathrm{CO}_{2}$ equivalent, in accordance with the Swiss building material database "Oekobilanzdaten im Baubereich" by KBOB [93]. Respectively, a GWP of $14.5 \mathrm{~kg}_{\mathrm{CO} 2-\mathrm{e}} \mathrm{kg}^{-1}$ was adopted for XPS, $1.13 \mathrm{~kg}_{\mathrm{CO} 2 \mathrm{e}} \mathrm{kg}^{-1}$ for the mineral wool and $0.257 \mathrm{~kg}_{\mathrm{CO} 2-\mathrm{e}} \mathrm{kg}^{-1}$ for the cellulose fiber. As for the windows, the glazed area was assumed to be $77 \%$ for double glazing and $73 \%$ for triple glazing, in agreement with Hoellinger et al. [94], and GWP values of $18.02 \mathrm{~kg}_{\mathrm{CO} 2 \mathrm{e}} \mathrm{kg}^{-1}$ and $25.62 \mathrm{~kg}_{\mathrm{CO} 2 \mathrm{e}} \mathrm{kg}^{-1}$ were calculated accordingly. 


\subsubsection{Objective Functions}

The adopted objective function in multi-objective optimization involved three objectives to minimize, dealing with energy, economic and sustainability performance.

Energy performance was characterized in terms of annual energy demand for space heating and was determined as a direct CitySim output.

Economic viability of the proposed EEMs was assessed in terms of differential net present value $(N P V)$ with respect to the $B A U$ scenario, according to the framework proposed in European regulation EU 244/2012 [95]. The NPV was evaluated for a 30-year time period, adopting a real discount rate $i=3 \%$. Only those different costs with respect to the $B A U$ scenario were accounted for. Regarding the price of the district heating, an average tariff of $0.064 \mathrm{EUR}_{\mathrm{kWh}}{ }^{-1}$ was assumed from the energy supply company price list; fixed components of the energy price were neglected since they were determined when the buildings were connected to the district heating network and are independent of the EEMs impact-i.e., the occupants pay the same energy fixed-price components in both $B A U$ and retrofitted scenarios. In agreement with the current Italian law [96], the value-added tax was considered equal to $10 \%$. Initial investment costs $I$ were calculated as a function of the chosen EEMs and expressed as negative cash flows. In contrast, annual savings $C_{\text {saved }}$ - calculated as the difference between the BAU annual costs for space heating and those of the retrofitted case, were treated as positive cash flows. Additional costs for scheduled maintenance were not considered, since the assessed 30-year period is supposed to be short enough to avoid major interventions, such as new substitution of windows or remaking of the external insulation layer. Net present value of each retrofit solution was calculated using Equation (4).

$$
N P V(i, N)=I+\sum_{t=0}^{N} \frac{C_{\text {saved }}}{(1+i)^{t}}
$$

As a consequence of how the NPV is defined, a positive NPV indicates a convenient investment, i.e., with savings larger than the initial investment cost.

The sustainability objective was assessed in terms of net accumulated saved $\mathrm{CO}_{2}$ emissions $\left(S_{\mathrm{CO} 2}\right)$ during the same analysis period considered in the economic part (30 years). Since this neighborhood is served by a district heating network fueled by waste heat valorization, the saved $\mathrm{CO}_{2}$ emissions were calculated, as shown in Equation (5), by multiplying the energy saving by the reference emission factor of $0.17 \mathrm{~kg}_{\mathrm{CO} 2 \mathrm{e}} \mathrm{kWh}_{\mathrm{t}}{ }^{-1}$ indicated in the local law DGP 235/2020 [97]. Furthermore, embodied and installation $\mathrm{CO}_{2}$ emissions $G W P_{\text {tot }}$ were also included in the multi-year balance and, adopting the same rule explained in the economic part, were attributed a negative sign, in contrast with the positive sign of the saved $\mathrm{CO}_{2}$ emissions during building operation.

$$
S_{\mathrm{CO}_{2}}=G W P_{t o t}+\sum_{t=0}^{N} \mathrm{CO}_{2, \text { saved, } t}
$$

\subsubsection{Multi-Objective Optimization and Decision Variables}

After a preliminary parametric analysis, a comprehensive multi-objective optimization was run. In both cases, the three objectives presented in Section 3.3.3 were evaluated and EEMs assigned independently to the three clusters of buildings, each one characterized by its own building envelope archetype. Simulations were run on a workstation computer (Intel core i7-4930K 6 cores CPU @3.40GHz and 32 GB RAM), each one lasting approximately $40 \mathrm{~min}$.

The preliminary parametric analysis was performed primarily with an exploratory purpose, considering a limited number of decision variables and alternative EEMs in order to assess, on one hand, the magnitude of the achievable energy savings, and, on the other hand, the computation requirements. In detail, besides the installation of more efficient windows, only one type of material (extruded polystyrene, XPS) was considered for the 
external insulation of the opaque envelope components. Each solution was characterized by means of 6 decision variables:

- $\quad x_{1}, x_{2}, x_{3}$ expressing the insulation thickness for Archetypes 1, 2 and 3 ("high", i.e., $20 \mathrm{~cm}$, or "low", i.e., the minimum requirement),

- $y_{1}, y_{2}, y_{3}$ indicating the window type, respectively, for Archetypes 1,2 and 3, with four alternatives each.

Due to the low number of combinations, i.e., 512, a full factorial approach was adopted and a specific code was written in $\mathrm{C}++$ and coupled with the CitySim solver.

In order to fully characterize the space of retrofitting strategies, the multi-objective optimization (Figure 3) also included different insulation materials with differing unitary costs and environmental impact, leading to nine decision variables in total. Besides the six decision variables introduced above, the following ones were included:

- $z_{1}, z_{2}, z_{3}$, expressing the type of insulation material for Archetypes 1, 2 and 3 (XPS, mineral wool or cellulose fiber),

with a total of 13,824 combinations.

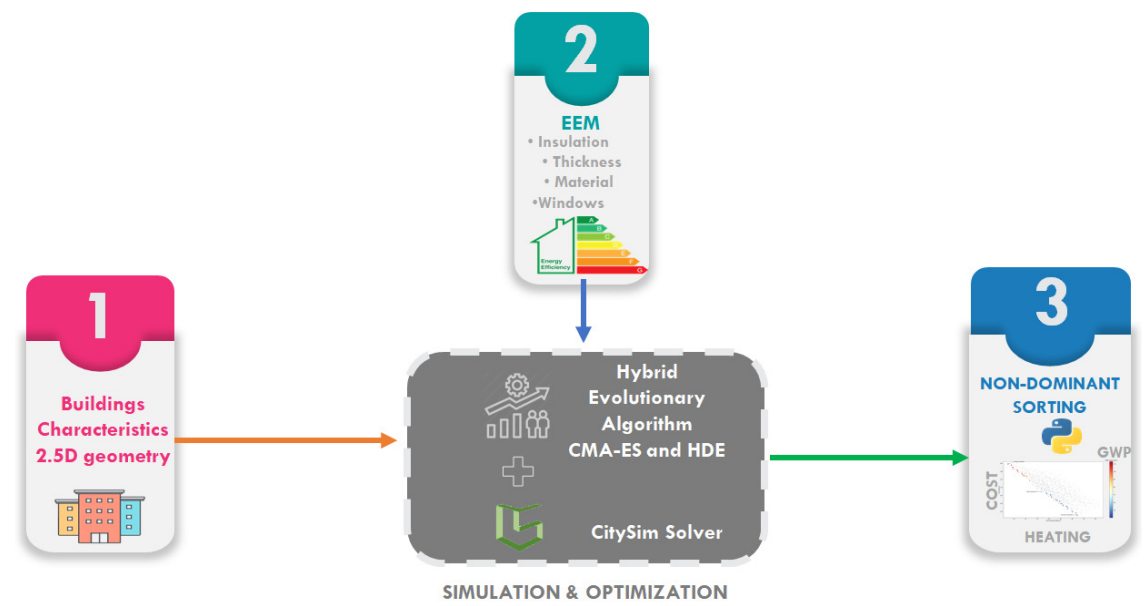

Figure 3. Flowchart diagrams for the development of optimization process using hybrid evolutionary algorithm.

Since parametric simulations were not a viable solution in this case, we used a hybrid evolutionary algorithm based on covariance matrix adaptation strategies (CMA-ES) and hybrid differential evolution ( $H D E$ ) evolutionary algorithms. The hybrid evolutionary algorithm combines the advantages of both $C M A-E S$ and $H D E$, and was developed with the goal to simulate and optimize the sustainability of urban environments $[98,99]$. The algorithm works with two distinct populations, with $\mu$ individuals and (NP-nt) individuals, respectively, for $H D E$ and $C M A-E S$. It starts with the $C M A-E S$ on a random population for $g_{1}$ generations, feeding the best $n t$ individuals of each step to the population of $H D E$; the missing (NP-nt) individuals in the population of $H D E$ are randomly generated. Then, the algorithm proceeds for $g_{2}$ generations with the HDE. The best $\mu$ and (NP-nt) individuals of the last $H D E$ generation are used to assess if the termination criterion (either a given number of iterations or a function threshold) is met. If that occurs, the algorithm stops, otherwise it loops and continues with CMA-ES.

The hybrid evolutionary algorithm was tested using standard benchmark tests, observing that the $H D E$ component brings a robustness in finding the global minimum and the CMA-ES component ensures a faster convergence $[98,99]$.

\section{Results and Discussion}

The simulated results are presented and discussed in this section. As a first step, the heating demand for the business as usual scenario is shown, for both 2015 and 2050 weather conditions. Then, the results of the multi-objective optimizations obtained considering the 
future climate are described and commented on, focusing on the optima belonging to the Pareto surface. In what follows, all the obtained results are reported as normalized with respect to the total floor area of the buildings in the case study district.

\subsection{Business as Usual Scenario}

The BAU scenario did not consider any intervention applied to the case study district and just projected the current situation into the 2050 climate condition. The future weather file, developed as in Section 3.3.2, included the effects of climate change, i.e., an increase of local ambient temperature and a consequent reduction of heating energy demand. Specifically, while $98 \mathrm{kWh} \mathrm{m}^{-2} \mathrm{a}^{-1}$ were simulated with the $2015 A M Y, 91 \mathrm{kWh} \mathrm{m}^{-2} \mathrm{a}^{-1}$ were observed in the case of the 2050 weather file. The registered $7 \%$ reduction, i.e., about $7 \mathrm{kWh} \mathrm{m}^{-2} \mathrm{a}^{-1}$, is attributable just to climate change itself. The same applies to the annual costs for space heating (from 6.9 EUR m${ }^{-2}$ to $6.4 \mathrm{EUR} \mathrm{m}^{-2}$ ) and to the corresponding annual $\mathrm{CO}_{2}$ emissions (from $16.7 \mathrm{kgCO}_{\mathrm{Ce}} \mathrm{m}^{-2}$ to $15.5 \mathrm{kgCO}_{\text {-e }} \mathrm{m}^{-2}$ ).

\subsection{Multi-Objective Optimization}

\subsubsection{Preliminary Parametric Analysis}

All 512 combinations resulting for the preliminary parametric analysis are presented in the 3D chart of Figure 4 (left), which depicts a 3D surface encompassing all solutions and illustrates energy, economic and environmental performances. As it is possible to notice in the NPV-heat demand plane (Figure 4, right), the heating demand can be reduced with the considered sets of EEMs between 48 and $65 \mathrm{kWh} \mathrm{m}^{-2} \mathrm{a}^{-1}$ from $91 \mathrm{kWh} \mathrm{m}^{-2} \mathrm{a}^{-1}$, i.e., by $46 \%$ and $29 \%$ with respect to the $2050 B A U$ scenario. All NPV values are negative and in the range between -110 and $-135 \mathrm{EUR} \mathrm{m}^{-2}$, meaning that the energy renovation investment never pays for itself for this case study. Indeed, as explained in Section 3.3.3, negative NPVS indicate that these renovations are not economically convenient and require public subsidization to promote their application. However, the balance of the saved $\mathrm{CO}_{2}$ emissions is always positive and in the range between 55 and $139 \mathrm{kgCO}_{\mathrm{e}} \mathrm{e} \mathrm{m}^{-2}$.
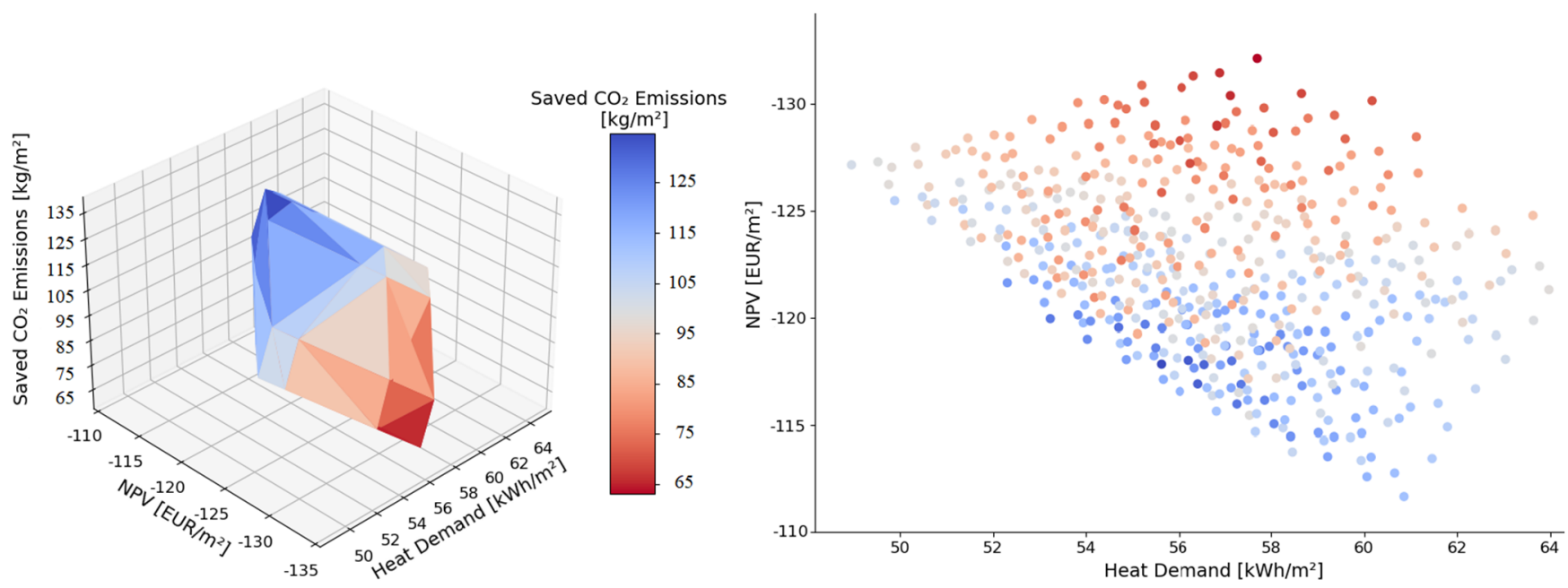

Figure 4. Simulation results for the preliminary parametric analysis: energy demand for space heating, net present value and saved $\mathrm{CO}_{2}$ emissions normalized per floor area for the whole district.

Of 512 tested combinations, 38 belong to the Pareto surface, leading to solutions with an annual heating demand ranging from 48 to $61 \mathrm{kWh} \mathrm{m}^{-2} \mathrm{a}^{-1}, N P V s$ from -111 to -127 EUR $\mathrm{m}^{-2}$ and saved $\mathrm{CO}_{2}$ emissions from 89 to $139 \mathrm{kgCO}_{\mathrm{C}-\mathrm{e}} \mathrm{m}^{-2}$.

Figure 5 shows the projection of the Pareto surface found with this preliminary parametric analysis on the NPV-heat demand plane (Figure 5, top) and on the NPV-saved $\mathrm{CO}_{2}$ emissions plane (Figure 5, bottom). 

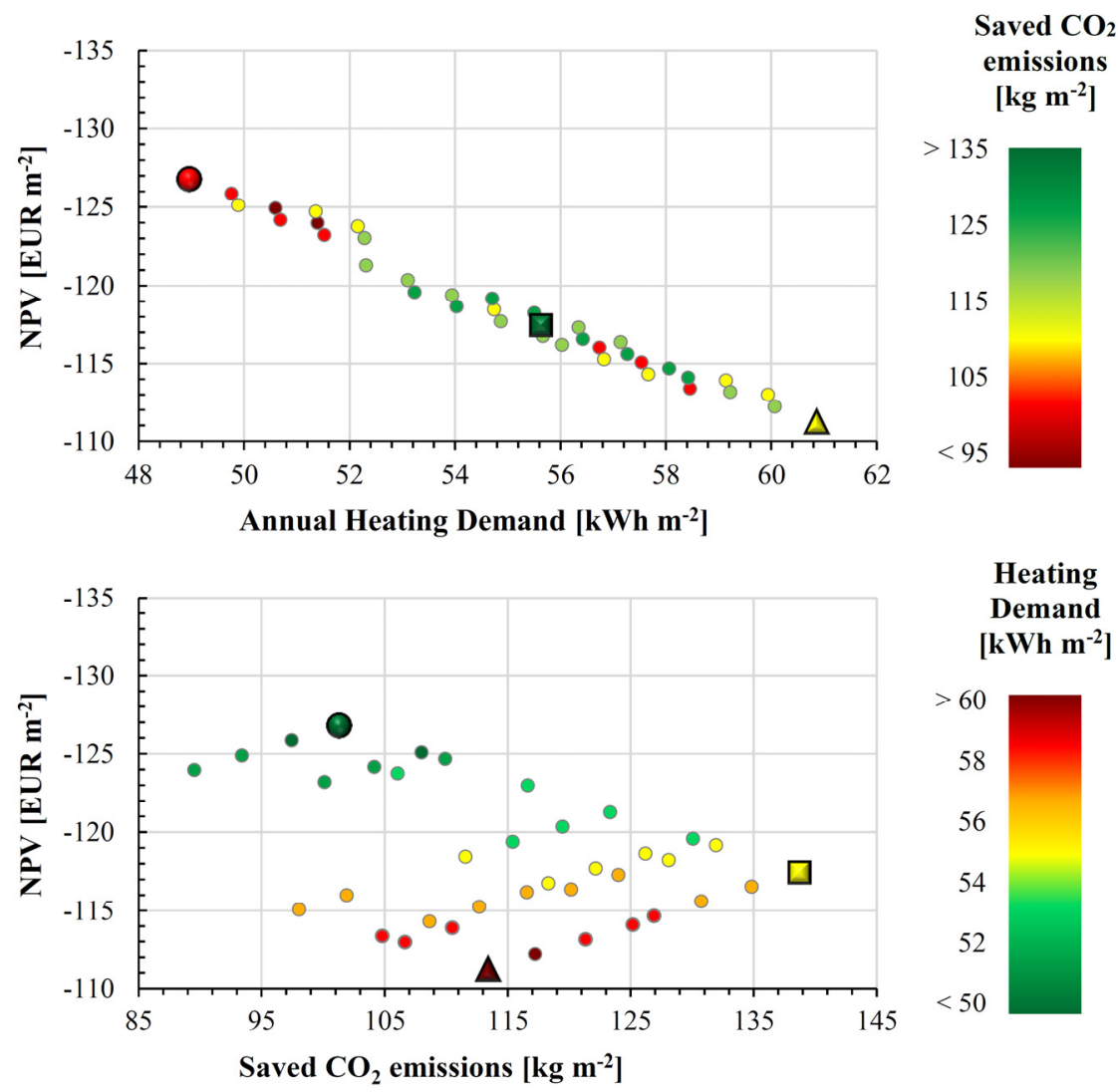

Figure 5. Projections of the Pareto surface on the NPV-heat demand plane (top) and on the NPVsaved $\mathrm{CO}_{2}$ emissions plane (bottom). Solutions are colored according to the saved $\mathrm{CO}_{2}$ emissions (top) and the heating demand (bottom). The energy optimum is represented by a larger circle, the economic optimum by a triangle and the environmental optimum by a square.

By focusing on the Pareto surface, it can be observed that the energy optimum, i.e., the solution which leads to the best energy performance, is the same for all building envelope archetypes and is characterized by highly insulated roofs and walls ( $+20 \mathrm{~cm}$ of XPS) and TH windows (triple glazing with high solar heat gain coefficient). Specifically, the choice of $T H$ windows can be explained with their ability to insulate more, compared to the available alternatives, while ensuring a higher exploitation of solar gains to reduce the heating needs. The energy optimum solution can reduce the annual heating demand to $49 \mathrm{kWh} \mathrm{m}^{-2} \mathrm{a}^{-1}$, corresponding to around $46 \%$ energy savings, at a cost of an investment of $185 \mathrm{EUR} \mathrm{m}^{-2}$, a NPV of -127 EUR $\mathrm{m}^{-2}$, but with $101 \mathrm{~kg}_{\mathrm{CO} 2-\mathrm{e}} \mathrm{m}^{-2}$ of saved emissions compared to the 2050 BAU scenario.

In contrast, the solution in the Pareto surface allowing the best economic result, i.e., the economic optimum with a NPV of $-111 \mathrm{EUR} \mathrm{m}^{-2}$, shows the presence of the prescribed minimum insulation coupled with $D H$ windows, i.e., double glazing and high $S H G C$, for all building envelope archetypes - the cheapest one among the four available alternatives. In this case, the reduction of the heating demand with respect to the $2050 \mathrm{BAU}$ scenario is only $34 \%$ (i.e., annual heating demand of $60 \mathrm{kWh} \mathrm{m}^{-2} \mathrm{a}^{-1}$ ) and the saved $\mathrm{CO}_{2}$ emissions equal to $113 \mathrm{~kg}_{\mathrm{CO} 2-\mathrm{e}} \mathrm{m}^{-2}$.

Finally, as regards the solution with the best environmental performance, i.e., the environmental optimum able to avoid $139 \mathrm{~kg}_{\mathrm{CO} 2-\mathrm{e}} \mathrm{m}^{-2}$ of emission with respect to the 2050 $B A U$ scenario, it combines the features of energy and economic optima. Indeed, this solution recommends the adoption of the minimum required insulation and the installation of $T H$ windows, resulting in 38\% energy savings for space heating (i.e., annual heating demand of $56 \mathrm{kWh} \mathrm{m}^{-2} \mathrm{a}^{-1}$ ) but at a lower investment cost compared to the energy optimum (i.e., an investment of $166 \mathrm{EUR} \mathrm{m}^{-2}$ and a NPV of $-117.5 \mathrm{EUR} \mathrm{m}^{-2}$ ). 
The preliminary parametric analysis allows us to observe some important findings regarding the proposed EEMs. First, it can be noticed that, although improvements are registered for both energy and sustainability performance for the considered case study district, no intervention is economically viable without public subsidization. Second, the economic optimum shows a better sustainability performance than the energy optimum. This is a consequence of the type of insulation material chosen for the preliminary parametric analysis, the XPS, characterized by a relatively high GWP compared to some other alternatives in the market.

\subsubsection{Comprehensive Multi-Objective Optimization}

In consideration of the findings of the preliminary parametric analysis, it was found worthwhile to run a comprehensive multi-objective optimization to explore the impact of more alternatives, with a better environmental impact and, thus, more interesting for public authorities in the framework of a subsidization plan. Taking into account that $40 \mathrm{~min}$ are required to evaluate a single solution vector of $E E M s$ with the available workstation and that the comprehensive multi-objective optimization comprises 13,824 alternatives, the parametric approach was assumed impractical. Consequently, the hybrid evolutionary algorithm mentioned in Section 3.3.4 was run for about 14 days in order to assess a total of 2400 variants (Figure 6), with 57 of them belonging to the Pareto surface.
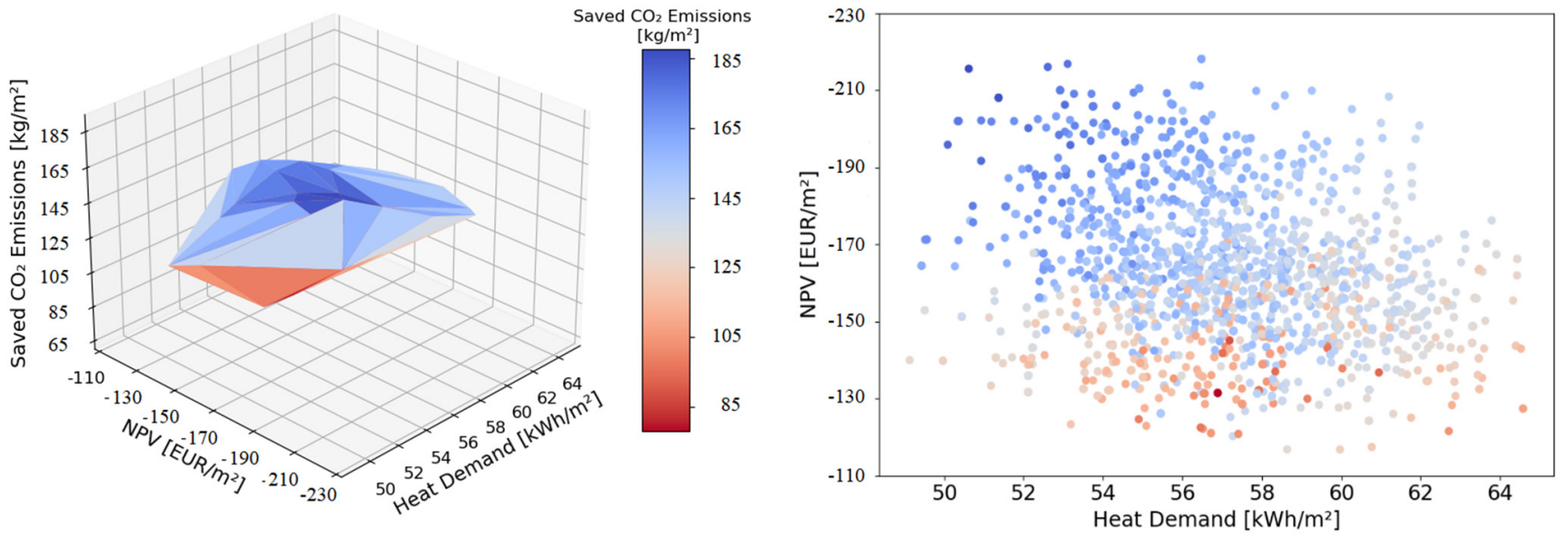

Figure 6. Simulation results for the hybrid evolutionary algorithm multi-objective optimization.

Compared to the findings of the previous analysis, the energy savings with respect to the 2050 baseline value show a similar range, from $26 \%$ to $46 \%$. Furthermore, the NPV is still negative for all the tested solutions, confirming the economic unsustainability of each intervention of the proposed case study. However, this multi-objective optimization underlines a higher potential in terms of saved $\mathrm{CO}_{2}$ emissions, reaching $191 \mathrm{~kg}_{\mathrm{CO} 2 \text {-e }} \mathrm{m}^{-2}$. As expected, the adoption of materials with lower GWP can be greatly beneficial to the sustainability performance goals. Nevertheless, those are generally more expensive solutions and the NPV can range from -110 to $-220 \mathrm{EUR} \mathrm{m}^{-2}$.

Figure 7 depicts the projections of the Pareto surface on the $N P V$-heat demand plane (top, with the solutions belonging to the Pareto surface colored according to the saved $\mathrm{CO}_{2}$ emissions) and on the $\mathrm{NPV}$-saved $\mathrm{CO}_{2}$ emissions plane (bottom, with the solutions belonging to the Pareto surface colored according to the annual heating demand). In both projections, a green-colored solution represents a better performance (in terms of either sustainability or energy efficiency) compared to a red one. In Figure 7, the energy, the economic and the environmental optima are marked, respectively, with a large circle, a triangle and a square. 

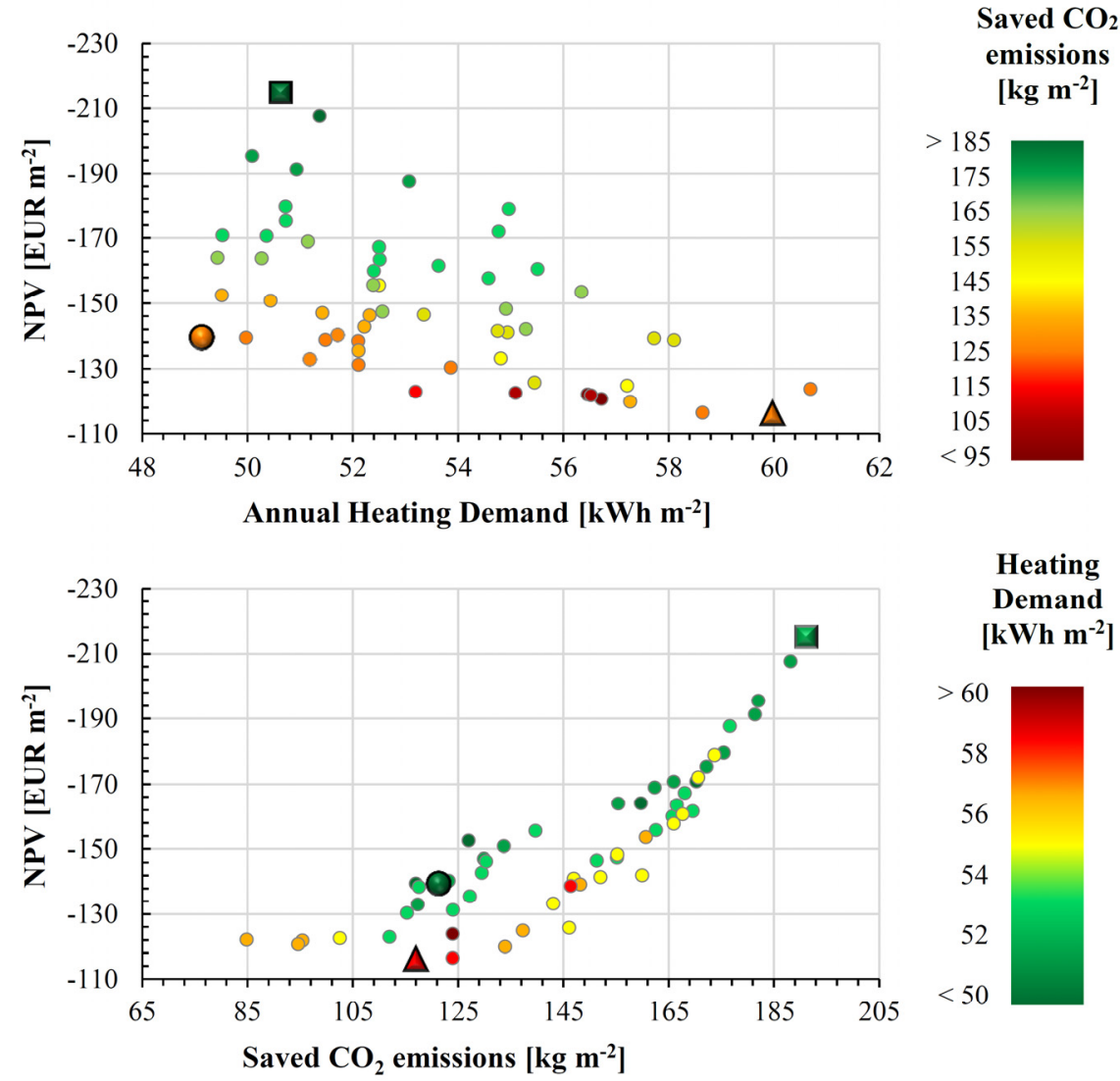

Figure 7. Projections of the Pareto surface on the NPV-heat demand plane (top) and on the NPVsaved $\mathrm{CO}_{2}$ emissions plane (bottom). Solutions are colored according to the saved $\mathrm{CO}_{2}$ emissions (top) and the heating demand (bottom). The energy optimum is represented by a larger circle, the economic optimum by a triangle and the environmental optimum by a square.

The energy optimum found with the multi-objective optimization is similar to the one obtained in the preliminary parametric analysis. The maximum insulation thickness and the installation of $T H$ windows are recommended but, while for Cluster 1 and Cluster 2 the XPS is chosen as insulation material, for Cluster 3 the mineral wool is indicated. The EEMs of the energy optimum allow $49.1 \mathrm{kWh} \mathrm{m}^{-2} \mathrm{a}^{-1}$ of annual heating demand and $121 \mathrm{~kg}_{\mathrm{CO} 2-\mathrm{e}}$ $\mathrm{m}^{-2}$ of saved $\mathrm{CO}_{2}$ emissions to be achieved, with an NPV of $-139.6 \mathrm{EUR} \mathrm{m}^{-2}$. Comparing this optimum with the one obtained in the preliminary parametric analysis, it can be noticed that it is slightly worse in terms of energy performance $\left(+0.1 \mathrm{kWh} \mathrm{m}^{-2} \mathrm{a}^{-1}\right)$, less economically convenient ( $\triangle N P V$ equal to $-12.8 \mathrm{EUR} \mathrm{m}^{-2}$ ) but with a better sustainability performance (about $+20 \mathrm{kgCO}_{\mathrm{Ce}} \mathrm{m}^{-2}$ ).

As regards the economic optimum, the findings are similar. The EEMs of the economic optimum are the minimum XPS insulation thickness compatible for each cluster of buildings and $D L$ windows. The annual heating demand, the $N P V$ and the saved $\mathrm{CO}_{2}$ emissions for this solution are, respectively, $59.9 \mathrm{kWh} \mathrm{m}^{-2} \mathrm{a}^{-1},-116.4 \mathrm{EUR} \mathrm{m}^{-2}$ and $117 \mathrm{~kg}_{\mathrm{CO} 2 \mathrm{e}} \mathrm{m}^{-2}$. This means that this solution leads to slightly better energy and sustainability performances compared to the one found with the preliminary parametric analysis $\left(-0.1 \mathrm{kWh} \mathrm{m}^{-2} \mathrm{a}^{-1}\right.$ of heating demand and $+4 \mathrm{~kg}_{\mathrm{CO} 2 \mathrm{e}} \mathrm{m}^{-2}$ of saved $\mathrm{CO}_{2}$ emissions), with a slightly worse economic performance ( $\triangle N P V$ equal to $-5.1 \mathrm{EUR} \mathrm{m}^{-2}$ ).

The environmental optimum shows large differences compared to the one identified in the preliminary parametric analysis. The selected EEMs are the same for all clusters of buildings, with the maximum insulation thickness of cellulose fiber and $T H$ windows. The annual heating demand is $50.6 \mathrm{kWh} \mathrm{m}^{-2} \mathrm{a}^{-1}$, very close to the one of the energy optimum, and the saved $\mathrm{CO}_{2}$ emissions are $191 \mathrm{~kg}_{\mathrm{CO}-\mathrm{e}} \mathrm{m}^{-2}$. The $N P V$, equal to $-215.2 \mathrm{EUR} \mathrm{m}^{-2}$, is the worst in the Pareto surface. 
The optima identified in the current optimization are not dominated by those found in the preliminary parametric analysis, nor is the opposite true. From a detailed scrutiny of all EEMs belonging to the Pareto surface and of all EEMs processed in the comprehensive multi-objective optimization, it was observed that those solutions were not simulated, since algorithm convergence was already reached (i.e., minimum of 2400 iterations and, for each goal, improvement of the optimum by $1 \%$ with respect to the previous generations). It can be speculated that, in the case of analysis of all possible alternatives, those would be identified and included in the Pareto surface as well. Furthermore, while environmental optima are clearly different, energy and economic optima of both preliminary parametric analysis and multi-objective optimization are characterized by very similar energy and economic performances and recommended EEMs. In particular, the prevalent selection of XPS in both cases can be explained because: (1) on one hand, it has a lower thermal conductivity compared to the other two alternatives presented in Section 3.3.2, i.e., mineral wool and cellulose fiber, and the same maximum thickness is considered regardless of the type of insulation material, ensuring in such a way the achievement of higher thermal resistances adopting XPS; (2) on the other hand, XPS has the lowest price among the proposed insulation materials.

Analyzing the distribution of the solutions of the Pareto surface in the NPV-heat demand and in the $N P V$-saved $\mathrm{CO}_{2}$ emissions planes, some general considerations can be drawn. In particular, it can be observed that:

- Two groups of solutions leading to high energy performance are present in the NPVsaved $\mathrm{CO}_{2}$ emissions plane (see the green colored dots)-one is positioned in the top-right region of the chart (i.e., poor economic performance but high sustainability performance) and the other is located in the bottom-central region of the chart (i.e., better economic performance but moderate sustainability performance).

- The solutions ensuring the best economic performance, although still economically inconvenient, can be detected in the bottom regions of both charts. While their sustainability performance is poor, a wide range of energy performances can be achieved, some of them very close to the energy optimum.

- Finally, the solutions which are able to maximize the sustainability performances are in the top regions of both charts-i.e., they are the most expensive solutions. Nevertheless, some of them can easily allow for high energy performance as well.

Tables 5-7 report the frequencies of the EEMs present in the Pareto surface, distinguishing the three clusters of buildings in the case study district. For more than half of the Pareto solutions for Cluster 1 and Cluster 2, XPS is the preferred choice, while this is true for mineral wool insulation in case of Cluster 3. As a whole, insulation materials which are more sustainable are generally suggested for Cluster 3 by the Pareto solutions. The maximum insulation thickness is recommended for more than $2 / 3$ of the Pareto solutions for Cluster 1. In contrast, the thicknesses sufficient to satisfy the national law requirements are more frequently found for Cluster 2 and Cluster 3. Finally, triple glazing with high SHGC is the predominant solution in the Pareto surface, independent of the selected cluster of buildings.

Table 5. Distributions of the selected type of insulation in the Pareto surface, distinguished by cluster of buildings. In grey those values with the largest frequencies.

\begin{tabular}{cccc}
\hline Type of Insulation & Cluster 1 & Cluster 2 & Cluster 3 \\
\hline XPS & $51 \%$ & $53 \%$ & $19 \%$ \\
\hline Mineral Wool & $35 \%$ & $33 \%$ & $49 \%$ \\
\hline Cellulose Fiber & $14 \%$ & $14 \%$ & $32 \%$ \\
\hline
\end{tabular}


Table 6. Distributions of the selected insulation thicknesses in the Pareto surface, distinguished by cluster of buildings. In grey those values with the largest frequencies.

\begin{tabular}{cccc}
\hline Insulation Thickness & Cluster 1 & Cluster 2 & Cluster 3 \\
\hline Maximum & $67 \%$ & $32 \%$ & $39 \%$ \\
\hline Minimum & $33 \%$ & $68 \%$ & $61 \%$ \\
\hline
\end{tabular}

Table 7. Distributions of the selected glazing systems in the Pareto surface, distinguished by cluster of buildings. In grey those values with the largest frequencies.

\begin{tabular}{cccc}
\hline Type of Window & Cluster 1 & Cluster 2 & Cluster 3 \\
\hline$D H$ & $5 \%$ & $12 \%$ & $18 \%$ \\
\hline$D L$ & $0 \%$ & $9 \%$ & $0 \%$ \\
\hline$T H$ & $86 \%$ & $72 \%$ & $68 \%$ \\
\hline$T L$ & $9 \%$ & $7 \%$ & $14 \%$ \\
\hline
\end{tabular}

Taking into account all the above, it can be concluded that the introduction of new insulating materials into the list of EEMs significantly altered the shape of the Pareto surface, as well as the choices available to the policy maker. The maximization of the energy performance can be achieved at a relatively low investment, considering the range of investments seen for the space of optimal solutions. However, in that scenario the sustainability performance is modest. If the goal is to enhance both energy and sustainability performances, some suitable sets of EEMs can be found, even if that implies important investments. Finally, while for energy, economic and sustainability optima the differences between the clusters of buildings are generally null or limited, more complex sets of solutions can be observed by analyzing the other points in the Pareto surface, introducing opportunities for the definition of more complex and detailed subsidization strategies.

\subsection{Additional Energy Efficiency Measures}

In the previous sections, it has been observed that EEMs involving just the building envelope can lead to energy savings of up to $46 \%$, in the best case, for the considered district. Taking into account the specific features of the analyzed case study, i.e., the presence of a district heating network, additional measures were considered just for the ventilation. Consequently, a new scenario was run, starting from the energy optimum of Section 4.2.2 and also including in the model mechanical ventilation systems with heat recovery. Specifically, each dwelling was equipped with a system characterized by an average sensible efficiency equal to 0.6 [100] and installation costs equal to EUR 6000 as in [92].

The results of this simulation showed a significant reduction of the average surface building energy demand for space heating of the district, from $49.1 \mathrm{kWh} \mathrm{m}^{-2} \mathrm{a}^{-1}$ to $27.2 \mathrm{kWh} \mathrm{m}^{-2} \mathrm{a}^{-1}$, corresponding to about $70 \%$ energy savings compared to $2050 \mathrm{BAU}$ scenario. Although the initial investment increased, the NPV improved by reaching

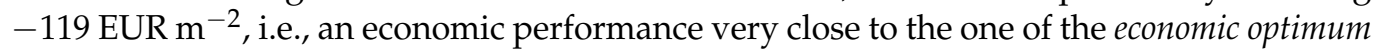
discussed in Section 4.2.2. Finally, the sustainability performance almost doubled, moving from $121 \mathrm{~kg}_{\mathrm{CO} 2-\mathrm{e}} \mathrm{m}^{-2}$ to $233.1 \mathrm{~kg}_{\mathrm{CO} 2-\mathrm{e}} \mathrm{m}^{-2}$ of saved $\mathrm{CO}_{2}$ emissions.

\subsection{Further Considerations on Energy Demand for Space Conditioning}

As observed in Section 3.3.1 and 4.1, climate change can bring an increase of the average ambient temperature, with a reduction of the $H D D_{18}$ of more than $175 \mathrm{~K}$ d with respect to the calibration-validation period. Considering the year 2015, $\triangle H D D_{18}$ is $220 \mathrm{~K} \mathrm{~d}$ and the energy demand for space heating drops by around $7 \%$.

The opposite trend is observed for the cooling degree days, with an increase of $C D D_{18}$ equal to $137 \mathrm{~K}$ d with respect to the 2012-2015 period. Nevertheless, if 2012 and 2015 are considered, the variation of $C D D_{18}$ is more limited. Analyzing the $B A U$ scenario, the cooling needs move from a value of $7.55 \mathrm{kWh} \mathrm{m}^{-2} \mathrm{a}^{-1}$ in 2015 to $16 \mathrm{kWh} \mathrm{m}^{-2} \mathrm{a}^{-1}$ in 2050 , i.e., more than double. 
In this context, the solutions adopted to enhance energy efficiency for space heating give a negligible contribution: indeed, if the energy optimum from the comprehensive multi-objective optimization is considered, cooling needs equal to $13.4 \mathrm{kWh} \mathrm{m}^{-2} \mathrm{a}^{-1}$ can be observed. The limited reduction compared to the $B A U$ scenario can be explained by the presence of both windows with lower SHGC and highly insulated opaque elements, reducing the indoor transmission of the absorbed solar gains. Furthermore, ventilation and infiltration rates are still sufficiently high to prevent the risk of overheating in the analyzed case study.

As a whole, although the energy needs for space cooling remain remarkably lower than those for space heating in the 2050 scenario, their growth has to be carefully taken into account, in order to adopt suitable measures and develop proactive energy policies. Indeed, even if the climate of Bolzano is currently heating-dominated, climate change is already making hot summer periods longer and more frequent. Consequently, the relative importance of the energy demand for space cooling is increasing, and the local 2050 climate is expected to share some similarities with some other Italian Mediterranean cities, characterized by both hot summer and cold winter periods.

\section{Conclusions}

In this paper, the potential of urban scale energy modeling tools coupled with multiobjective optimization was discussed in the framework of the optimal selection of energy efficiency measures for building energy retrofitting. In particular, to cope with the complexity and heterogeneity of urban districts, as well as with frequent issues brought by the lack of complete data inputs, a new methodology was proposed, combining the detailed geometric characterization of urban simulation tools with the simplification provided by "building archetype" modeling, thus allowing the development of models sufficiently robust for the definition of retrofit interventions at district scale driven by multi-objective optimization.

The proposed methodology was applied to a case study, a residential neighborhood built in the 1990s and served by a district heating network, located in the heating-dominated climate of Bolzano, Northern Italy. Three goals were considered for optimization, focusing on energy, economic and environmental performances, and expressed in terms of annual energy demand for space heating, net present value and saved $\mathrm{CO}_{2}$ emissions during a 30year period for the whole district and each energy retrofitting alternative. Simulations were run with CitySim and energy efficiency measures were addressed just to the improvement of the quality of the building envelope, accounting for the minimum requirements set by current Italian law. Specifically, four high performance glazing systems (double and triple glazing, with high or low $S H G C$ ), three kinds of insulation materials (extruded polystyrene, mineral wool and cellulose fiber), and two insulation thicknesses (the minimum prescribed by the law and a maximum of $20 \mathrm{~cm}$ ) were included among the alternative energy efficiency measures. Differing from conventional optimizations, in this research the future 2050 climate of Bolzano was adopted, determined with Meteonorm in agreement with the IPCC A2 BAU scenario.

The specific results for the selected case study showed that:

1. Climate change could have a significant impact on the energy performance of the selected case study district. Indeed, the simulations run with a 2050 climate projection showed a potential $7 \%$ reduction in heating demand, due to an increase in ambient temperature. In contrast, the energy needs for space cooling could achieve values more than double the current ones. Even if the energy requirements for space cooling are still projected to be lower than those for heating, their growth has to be carefully taken into account in the development of the local energy policies for buildings.

2. Each energy efficiency measure could improve the district energy performance. Nevertheless, most of solutions belonging to the Pareto surface range between 49 and $64 \mathrm{kWh} \mathrm{m}^{-2} \mathrm{a}^{-1}$ with respect to a baseline of $91 \mathrm{kWh} \mathrm{m}^{-2} \mathrm{a}^{-1}$ in 2050, which means 
that the proposed energy refurbishment, focused only on the building envelope, could bring just up to $46 \%$ reduction of the annual heating demand in the best case.

3. None of the proposed investments is sustainable from the economic point of view. Indeed, all net present values are negative, meaning that none of the energy retrofit alternatives can repay the initial investment in a 30 -year period. This could indicate that neither the cost of thermal energy for this neighborhood, lower than average because of the connection to the district heating network, nor the annual savings are sufficient to make the investment convenient. Consequently, if the policy maker is willing to promote its renovation, tailored subsidization strategies should be proposed.

4. All the energy efficiency measures could allow for a positive life-cycle balance of $\mathrm{CO}_{2}$ emissions. This means that annual savings could compensate for the embodied and installation $\mathrm{CO}_{2}$ emissions associated to the implementation of the energy efficiency measures. As a whole, the amount of avoided $\mathrm{CO}_{2}$ emissions is strictly dependent on the choice of insulation material and can range from $55 \mathrm{~kg}_{\mathrm{CO} 2-\mathrm{e}} \mathrm{m}^{-2}$ (extruded polystyrene) to $191 \mathrm{~kg}_{\mathrm{CO} 2-\mathrm{e}} \mathrm{m}^{-2}$ (cellulose fiber) during 30 years of operation. Again, considering that environmentally friendly solutions are characterized by higher unitary prices, targeted incentives can be useful for the definition of an urban energy policy aimed at promoting not only energy efficiency, but also sustainability goals.

5. Although minimal differences were registered between the energy efficiency measures selected in the cases of the three energy, economic and sustainability optima for the three clusters of buildings in the case study district, this is not true if the whole set of solutions belonging to the Pareto surface is studied. For instance, while extruded polystyrene is generally preferred for Cluster 1 and Cluster 2, more sustainable insulation materials, like mineral wool and cellulose fiber, are more frequently suggested for the renovation of Cluster 3 buildings. Furthermore, while insulation is often maximized for Cluster 1 buildings, the compliance with current national requirements is often judged sufficient in the case of Cluster 2 and Cluster 3. This could be exploited by policy makers to diversify subsidization strategies while pursuing a neighborhood or city-scale Pareto optimality.

6. As a whole, the results achieved are insufficient if compared with the European targets for an $80 \%$ reduction of energy demand by 2050 . Starting from the best refurbished case in terms of energy savings, an additional simulation was run, assuming the installation of a mechanical ventilation system. Both energy, economic and sustainability performances are found largely improved (i.e., $27.2 \mathrm{kWh} \mathrm{m}^{-2} \mathrm{a}^{-1},-119 \mathrm{EUR} \mathrm{m}^{-2}$, $233 \mathrm{~kg}_{\mathrm{CO} 2 \text {-eq }} \mathrm{m}^{-2}$ ), confirming that, for the analyzed case study, efficiency measures applied just to the building envelope were not enough and, at least, mechanical ventilation with heat recovery should be considered.

As observed, thanks to the application to a real case study, the proposed methodology allows the different trade-offs between the considered objectives and the implications arising from the prioritization of a given target to be discussed. Consequently, it can be successfully adopted to support the local decision makers in the development of efficient strategies to apply at city or district scale. Nevertheless, since the methodology was meant to be applied in a context of data scarcity and considered only long-term objectives, it could be suboptimal when short-term performance indicators and hourly or subhourly dynamics are the focus of the analysis. The refurbishment strategy obtained as a result of the proposed approach is indeed the first step, which can pave the way for more detailed analyses. However, for the investigation of complex solutions which require a more accurate knowledge of the daily pattern and schedules, the user is advised to put additional efforts towards the retrieval of comprehensive input data and the dedicated calibration and validation of the urban model.

As far as the specific findings for the case study are concerned, it should be remembered that they are strictly related to the analyzed neighborhood. Although generalization is difficult, some considerations about the achieved results and the selected energy efficiency measures can be extended to similar neighborhoods and climate conditions. 
Even if the application is currently in a heating-dominated climate, it should be underlined that it can be applied to any climate, as long as the focus is kept on long-term performance objectives-modifying the performance goals if necessary, and a suitable set of energy efficiency measures is defined.

In this context, districts in Italian Mediterranean climates, characterized in most cases by both heating and cooling demands, can represent a particularly interesting analysis with further complexity compared to the investigated case study of Bolzano. In those scenarios, it is recommended (i) to adopt a "total energy" approach, expressing the energy performance as primary energy, and (ii) to include a variety of measures able to address both the heating problem and the cooling one. The implementation of the proposed methodology can be particularly helpful for the policy makers of Mediterranean cities, who can choose the best solutions, considering the specificity of the local current or projected climate conditions.

Further developments of this research will be addressed for (1) its application to different case-studies, (2) the assessment of different sets of energy efficiency measures, including standard HVAC system components as well as $P V$ panels and other solutions for the local generation of renewable energy, in the perspective of developing "Net-Zero Energy Buildings" or "energy communities" in agreement with the European Directives 2019/944 and 2018/844, (3) the robustness analysis of the selected energy efficiency measures, considering in particular different climate scenario conditions, and (4) the study of the impact of different subsidization strategies, defined to prioritize a specific objective among those included in the multi-objective optimization.

Author Contributions: Conceptualization, G.P., A.G. and J.H.K.; methodology, F.H., G.P., A.G. and J.H.K.; software, F.H. and J.H.K.; formal analysis, F.H. and G.P.; writing-original draft preparation, F.H.; writing-review and editing, G.P., A.G. and J.H.K.; supervision, A.G. and J.H.K. All authors have read and agreed to the published version of the manuscript.

Funding: This study has been partially funded by the project "Klimahouse and Energy Production" in the framework of the programmatic-financial agreement with the Autonomous Province of BozenBolzano of Research Capacity Building. This work was supported by the Open Access Publishing Fund of the Free University of Bozen-Bolzano.

Acknowledgments: The Authors would also like to thank the KlimaHaus Agency for providing access to the building energy certificates and the Municipality of Bozen-Bolzano for the building energy consumption data.

Conflicts of Interest: The authors declare no conflict of interest.

\section{References}

1. United Nations. World Population Prospects: The 2017 Revision, Key Findings and Advance Tables; Department of Economics and Social Affairs PD, Ed.; United Nations: New York, NY, USA, 2017.

2. International Energy Agency (IEA). Energy Technology Perspectives 2012: Pathways to a Clean Energy System; International Energy Agency: Paris, France, 2012.

3. Nauclér, T.; Enkvist, P.-A. Pathways to a Low-Carbon Economy: Version 2 of the Global Greenhouse Gas. Abatement Cost Curve; McKinsey \& Company: 2009. Available online: https:/ /www.mckinsey.com/business-functions/sustainability/our-insights / pathways-to-a-low-carbon-economy (accessed on 18 August 2021).

4. Enkvist, P.-A.; Dinkel, J.; Lin, C. Impact of the Financial Crisis on Carbon Economics: Version 2.1 of the Global Greenhouse Gas Abatement Cost Curve; McKinsey \& Company, 2010. Available online: https://www.mckinsey.com/business-functions/sustainability/ourinsights /impact-of-the-financial-crisis-on-carbon-economics-version-21 (accessed on 18 August 2021).

5. Intergovernmental Panel on Climate Change (IPCC). Climate Change 2007: The Physical Science Basis. Contribution of Working Group I to the Fourth Assessment Report of the Intergovernmental Panel on Climate Change; Solomon, S., Qin, D., Manning, M., Chen, Z., Marquis, M., Averyt, K.B., Eds.; Cambridge University Press: Cambridge, UK; New York, NY, USA, 2007.

6. European Parliament and European Council. Directive 2012/27/EU of the European Parliament and of the Council of 25 October 2012 on Energy Efficiency, Amending Directives 2009/125/EC and 2010/30/EU and Repealing Directives 2004/8/EC and 2006/32/EC. OJEU 2012, L 315, 1-56. 
7. European Parliament and European Council. Directive (EU) 2018/844 of the European Parliament and of the Council of 30 May 2018 amending Directive 2010/31/EU on the Energy Performance of Buildings and Directive 2012/27/EU on Energy Efficiency. OJEU 2018, L 156, 75-91.

8. International Energy Agency (IEA). Energy Policies of IEA Countries; International Energy Agency: Paris, France, 2017.

9. Buildings Performance Institute Europe (BPIE). 97\% of Buildings in the EU Need to Be Upgraded; BPIE-Buildings Performance Institute Europe: Brussels, Belgium, 2017.

10. Directorate-General for Energy of the European Commission, IPSOS and Navigant. Comprehensive Study of Building Energy Renovation Activities and the Uptake of Nearly Zero-Energy Buildings in the EU: Final Report; European Commission: Brussels, Belgium, 2019.

11. Buildings Performance Institute Europe (BPIE). Long-Term Renovation Strategies and Local Building Renovation Initiatives: Case Studies from 8 Countries; BPIE-Buildings Performance Institute Europe: Brussels, Belgium, 2020.

12. Renovate Europe. Available online: https://www.renovate-europe.eu/ (accessed on 18 August 2021).

13. Architecture 2030. Roadmap to Zero Emissions-Architecture 2030; Architecture 2030: Santa Fe, Mexico, 2014.

14. Pérez-Lombard, L.; Ortiz, J.; González, R.; Maestre, I.R. A review of benchmarking, rating and labelling concepts within the framework of building energy certification schemes. Energy Build. 2009, 41, 272-278. [CrossRef]

15. Sulzer, M.; Orehounig, K.; Carp, V.; Gadola, R.; Knoeri, C.; Marquant, J.; Mavromatidis, G.; Mennel, S.; Murray, P.; Nakhle, C.; et al. Concept for next Generation of Technical Energy Regulations in Buildings. Energy Turnaround-Technical-Regulations EnTeR-Final Report Phase 1; EMPA—ETH Zürich: Dübendorf, Switzerland, 2019.

16. De Wilde, P. The Gap between predicted and measured energy performance of buildings: A framework for investigation. Automat. Constr. 2014, 41, 40-49. [CrossRef]

17. Ahn, K.U.; Kim, D.W.; Kim, Y.J.; Yoon, S.H.; Park, C.S. Issues to be solved for energy simulation of an existing office building. Sustainability 2016, 8, 345. [CrossRef]

18. Buildings Performance Institute Europe (BPIE). Building Renovation: A Kick-Starter for the EU Economy-Renovate Europe; BPIEBuildings Performance Institute Europe: Brussels, Belgium, 2020.

19. Ramesh, T.; Prakash, R.; Shukla, K.K. Life cycle energy analysis of buildings: An overview. Energy Build. 2010, 42, 1592-1600. [CrossRef]

20. Ghiassi, N. An Hourglass Approach to Urban Energy Computing. Ph.D. Thesis, Vienna University of Technology, Vienna, Austria, 2017.

21. Hong, T.; Chen, Y.; Luo, X.; Luo, N.; Lee, S.H. Ten questions on urban building energy modeling. Build. Environ. 2020, $168,106508$. [CrossRef]

22. Salom, J.; Pascual, J. Residential Retrofits at District Scale; InnoEnergy: Eindhoven, The Netherlands, 2018.

23. Reinhart, C.F.; Cerezo Davila, C. Urban building energy modeling-A review of a nascent field. Build. Environ. 2016, 97, 196-202. [CrossRef]

24. Carreras, J.; Boer, D.; Guillén-Gosálbez, G.; Cabeza, L.F.; Medrano, M.; Jiménez, L. Multi-objective optimization of thermal modelled cubicles considering the total cost and life cycle environmental impact. Energy Build. 2015, 88, 335-346. [CrossRef]

25. Hamdy, M.; Hasan, A.; Siren, K. A multi-stage optimization method for cost-optimal and nearly-zero-energy building solutions in line with the EPBD-recast 2010. Energy Build. 2013, 56, 189-203. [CrossRef]

26. Penna, P.; Prada, A.; Cappelletti, F.; Gasparella, A. Multi-objectives optimization of energy efficiency measures in existing buildings. Energy Build. 2015, 95, 57-69. [CrossRef]

27. Shao, Y.; Geyer, P.; Lang, W. Integrating requirement analysis and multi-objective optimization for office building energy retrofit strategies. Energy Build. 2014, 82, 356-368. [CrossRef]

28. Wang, C.; Kilkis, S.; Tjernström, J.; Nyblom, J.; Martinac, I. Multi-objective optimization and parametric analysis of energy system designs for the Albano University Campus in Stockholm. Procedia Eng. 2017, 180, 621-630. [CrossRef]

29. Harish, V.S.K.V.; Kumar, A. A review on modeling and simulation of building energy systems. Renew. Sustain. Energy Rev. 2016, 56, 1272-1292. [CrossRef]

30. Dorer, V.; Allegrini, J.; Orehounig, K.; Moonen, P.; Upadhyay, G.; Kämpf, J.H.; Carmeliet, J. Modelling the urban microclimate and its impact on the energy demand of buildings and building clusters. In Proceedings of the Building Simulation 2013, Chambery, France, 26-28 August 2013; Wurtz, E., Ed.; IBPSA: Toronto, ON, Canada, 2013.

31. Gros, A.; Bozonnet, E.; Inard, C.; Musy, M. Simulation tools to assess microclimate and building energy-A case study on the design of a new district. Energy Build. 2016, 114, 112-122. [CrossRef]

32. Keirstead, J.; Jennings, M.; Sivakumar, A. A review of urban energy system models: Approaches, challenges and opportunities. Renew. Sustain. Energy Rev. 2012, 16, 3847-3866. [CrossRef]

33. Kavgic, M.; Mavrogianni, A.; Mumovic, D.; Summerfield, A.J.; Stevanović, Z.M.; Djurović-Petrović, M.D. A review of bottom-up building stock models for energy consumption in the residential sector. Build. Environ. 2010, 45, 1683-1697. [CrossRef]

34. Perez, D.; Robinson, D. Urban energy flow modelling: A data-aware approach. In Digital Urban Modeling and Simulation. Communications in Computer and Information Science; Müller Arisona, S., Aschwanden, G., Halatsch, J., Wonka, P., Eds.; Springer: Berlin, Germany, 2012; Volume 242, pp. 200-220.

35. Swan, L.G.; Ugursal, V.I. Modeling of end-use energy consumption in the residential sector: A review of modeling techniques. Renew. Sustain. Energy Rev. 2009, 13, 1819-1835. [CrossRef] 
36. Sola, A.; Corchero, C.; Salom, J.; Sanmarti, M. Multi-domain urban-scale energy modelling tools: A review. Sustain. Cities Soc. 2020, 54, 101872. [CrossRef]

37. Bueno, B.; Pigeon, G.; Norford, L.K.; Zibouche, K.; Marchadier, C. Development and evaluation of a building energy model integrated in the TEB scheme. Geosci. Model Dev. 2012, 5, 433-448. [CrossRef]

38. Swan, L.G.; Ugursal, V.I.; Beausoleil-Morrison, I. Implementation of a Canadian residential energy end-use model for assessing new technology impacts. In Proceedings of the Building Simulation 2009, Glasgow, UK, 27-30 July 2009.

39. Chen, Y.; Hong, T.; Piette, M.A. Automatic generation and simulation of urban building energy models based on city datasets for city-scale building retrofit analysis. Appl. Energy 2017, 205, 323-335. [CrossRef]

40. Nouvel, R.; Brassel, K.H.; Bruse, M.; Duminil, E.; Coors, V.; Eicker, U.; Robinson, D. SimStadt, a new workflow-driven urban energy simulation platform for CityGML city models. In Proceedings of the International Conference CISBAT 2015 Future Buildings and Districts Sustainability from Nano to Urban Scale, EPFL, Lausanne, Switzerland, 9-15 September 2015; Scartezzini, J.-L., Ed.; EPFL Solar Energy and Building Physics Laboratory: Lausanne, Switzerland, 2015.

41. Remmen, P.; Müller, D.; Lauster, M.; Osterhage, T.; Mans, M. CityGML import and export for dynamic building performance simulation in Modelica. In Proceedings of the Building Simulation and Optimization 2016, Newcastle University, Newcastle upon Tyne, UK, 12-14 September 2016.

42. Reinhart, C.F.; Dogan, T.; Jakubiec, J.A.; Rakha, T.; Sang, A. Umi-an Urban Simulation Environment for Building Energy Use, Daylighting and Walkability. In Proceedings of the Building Simulation 2013, Chambery, France, 26-28 August 2013; Wurtz, E., Ed.; IBPSA: Toronto, ON, Canada, 2013.

43. Best, R.E.; Flager, F.; Lepech, M.D. Modeling and optimization of building mix and energy supply technology for urban districts. Appl. Energy 2015, 159, 161-177. [CrossRef]

44. Fonseca, J.A.; Nguyen, T.-A.; Schlueter, A.; Marechal, F. City Energy Analyst (CEA): Integrated framework for analysis and optimization of building energy systems in neighborhoods and city districts. Energy Build. 2016, 113, 202-226. [CrossRef]

45. Robinson, D.; Haldi, F.; Leroux, P.; Perez, D.; Rasheed, A.; Wilke, U. CitySim: Comprehensive micro-simulation of resource flows for sustainable urban planning. In Proceedings of the Building Simulation 2009, Glasgow, UK, 27-30 July 2009.

46. Bollinger, L.A.; Evins, R. HUES: A holistic urban energy simulation platform for effective model integration. In Proceedings of the International Conference CISBAT 2015 Future Buildings and Districts Sustainability from Nano to Urban Scale, EPFL, Lausanne, Switzerland, 9-15 September 2015; Scartezzini, J.-L., Ed.; EPFL Solar Energy and Building Physics Laboratory: Lausanne, Switzerland, 2015.

47. Baetens, R.; De Coninck, R.; Van Roy, J.; Verbruggen, B.; Driesen, J.L.J.; Helsen, L.M.L.; Saelens, D. Assessing electrical bottlenecks at feeder level for residential net zero-energy buildings by integrated system simulation. Appl. Energy 2012, 96, 74-83. [CrossRef]

48. Bergerson, J.; Muehleisen, R.T.; Bo Rodda, W.; Auld, J.A.; Guzowski, L.B.; Ozik, J.; Collier, N. Designing Future Cities: LakeSIM Integrated Design Tool for Assessing Short and Long Term Impacts of Urban Scale Conceptual Designs; ISOCARP Review 11; Nan, S., Reilly, J., Klass, F., Eds.; International Society of City and Regional Planners: Sura Mica, Romania, 2015.

49. Molitor, C.; Groß, S.; Zeitz, J.; Monti, A. MESCOS-A multienergy system cosimulator for city district energy systems. IEEE Trans. Ind. Inform. 2014, 10, 2247-2256. [CrossRef]

50. Keirstead, J.; Samsatli, N.; Shah, N. SynCity: An integrated tool kit for urban energy systems modelling. In Proceedings of the 5th Urban Research Symposium, Marseille, France, 28-30 June 2009.

51. Polly, B.; Kutscher, C.; Macumber, D.; Schott, M.; Pless, S.; Livingood, B.; Van Geet, O. From zero energy buildings to zero energy districts. In Proceedings of the 2016 ACEEE Summer Study on Energy Efficiency in Buildings: From Components to Systems, From Buildings to Communities, Pacific Grove, CA, USA, 21-26 August 2016.

52. Wetter, M.; Haves, P. A modular building controls virtual test bed for the integration of heterogeneous systems. In Proceedings of the SimBuild 2008, Berkeley, SF, USA, 30 July-1 August 2008.

53. UMEM-Consortium. SCCER Future Energy Efficient Buildings \& Districts; UMEM-Consortium: Zurich, Switzerland, 2014. Available online: http://www.sccer-feebd.ch/wp-content/uploads/703_UMEM_AAR-CCEM_20142.pdf (accessed on 18 August 2021).

54. Abbasabadi, N.; Ashayeri, M. Urban energy use modeling methods and tools: A review and an outlook. Build. Environ. 2019, 161, 106270. [CrossRef]

55. Cerezo, C.; Dogan, T.; Reinhart, C.F. Towards standardized building properties template files for early design energy model generation. In Proceedings of the 2014 ASHRAE/IBPSA-USA Building Simulation Conference, Atlanta, GA, USA, 10-12 September 2014.

56. Carnieletto, L.; Ferrando, M.; Teso, L.; Sun, K.; Zhang, W.; Causone, F.; Romagnoni, P.; Zarrella, A.; Hong, T. Italian prototype building models for urban scale building performance simulation. Build. Environ. 2021, 192, 107590. [CrossRef]

57. Kämpf, J.H.; Robinson, D. A simplified thermal model to support analysis of urban resource flows. Energy Build. 2007, 39, 445-453. [CrossRef]

58. Zekar, A.; El Khatib, S. Development and assessment of simplified building representations under the context of an urban energy model: Application to arid climate environment. Energy Build. 2018, 173, 461-469. [CrossRef]

59. Biljecki, F.; Stoter, J.; Ledoux, H.; Zlatanova, S.; Coltekin, A. Applications of 3D city models: State of the art review. ISPRS Int. J. Geo-Inf. 2015, 4, 2842-2889. [CrossRef]

60. Karmellos, M.; Mavrotas, G. Multi-objective optimization and comparison framework for the design of distributed energy systems. Energy Convers. Manag. 2019, 180, 473-495. [CrossRef] 
61. Maroufmashat, A.; Sattari, S.; Roshandel, R.; Fowler, M.; Elkamel, A. Multi-objective optimization for design and operation of distributed energy systems through the multi-energy hub network approach. Ind. Eng. Chem. Res. 2016, 55, 8950-8966. [CrossRef]

62. Falke, T.; Krengel, S.; Meinerzhagen, A.-K.; Schnettler, A. Multi-objective optimization and simulation model for the design of distributed energy systems. Appl. Energy 2016, 184, 1508-1516. [CrossRef]

63. Nault, E.; Waibel, C.; Carmeliet, J.; Andersen, M. Development and test application of the UrbanSOLve decision-support prototype for early-stage neighborhood design. Build. Environ. 2018, 137, 58-72. [CrossRef]

64. Wortmann, T.; Natanian, J. Multi-objective optimization for zero-energy urban design in China: A benchmark. In Proceedings of the SimAUD 2020, Vienna, Austria, 25-27 May 2020.

65. Camporeale, P.E.; Mercader-Moyano, P. Towards nearly zero energy buildings: Shape optimization of typical housing typologies in Ibero-American temperate climate cities from a holistic perspective. Sol. Energy 2019, 193, 738-765. [CrossRef]

66. Waibel, C.; Evins, R.; Carmeliet, J. Co-Simulation and optimization of building geometry and multi-energy systems: Interdependencies in energy supply, energy demand and solar potentials. Appl. Energy 2019, 242, 1661-1682. [CrossRef]

67. Vermeulen, T.; Knopf-Lenoir, C.; Villon, P.; Beckers, B. Urban layout optimization framework to maximize direct solar irradiation. Comput. Environ. Urban Syst. 2015, 51, 1-12. [CrossRef]

68. Yu, S.; Austern, G.; Jirathiyut, T.; Moral, M. Climatic formations: Evolutionary dynamics of urban morphologies. J. Asian Arch. Build. Eng. 2014, 13, 317-324. [CrossRef]

69. Luddeni, G.; Krarti, M.; Pernigotto, G.; Gasparella, A. An analysis methodology for large-scale deep energy retrofits of existing building stocks: Case study of the Italian office building. Sustain. Cities Soc. 2018, 41, 296-311. [CrossRef]

70. Murray, P.; Marquant, J.; Niffeler, M.; Mavromatidis, G.; Orehounig, K. Optimal transformation strategies for buildings, neighbourhoods and districts to reach CO2 emission reduction targets. Energy Build. 2020, 207, 109569. [CrossRef]

71. Jin, H.; Cui, P.; Wong, N.H.; Ignatius, M. Assessing the effects of urban morphology parameters on microclimate in Singapore to control the urban heat island effect. Sustainability 2018, 10, 206. [CrossRef]

72. Battini, F.; Pernigotto, G.; Gasparella, A. A parametric analysis of the impact of thermophysical, geometry and urban features on the energy demand of a simplified building shoebox model. In Proceedings of the Building Simulation 2021, Bruges, Belgium, 1-3 September 2021.

73. Luo, X.; Hong, T.; Tang, Y.-H. Modeling thermal interactions between buildings in an urban context. Energies 2020, 13, 2382. [CrossRef]

74. Chen, Y.; Hong, T.; Luo, X.; Hooper, B. Development of city buildings dataset for urban building energy modeling. Energy Build. 2019, 183, 252-265. [CrossRef]

75. Ali, U.; Shamsi, M.H.; Hoare, C.; Mangina, E.; O’Donnell, J. Review of urban building energy modeling (UBEM) approaches, methods and tools using qualitative and quantitative analysis. Energy Build. 2021, 246, 111073. [CrossRef]

76. Ferrando, M.; Causone, F.; Hong, T.; Chen, Y. Urban building energy modeling (UBEM) tools: A state-of-the-art review of bottom-up physics-based approaches. Sustain. Cities Soc. 2020, 62, 102408. [CrossRef]

77. Lara, R.A.; Pernigotto, G.; Cappelletti, F.; Romagnoni, P.; Gasparella, A. Energy audit of schools by means of cluster analysis. Energy Build. 2015, 95, 160-171. [CrossRef]

78. Pistore, L.; Pernigotto, G.; Cappelletti, F.; Gasparella, A.; Romagnoni, P. A stepwise approach integrating feature selection, regression techniques and cluster analysis to identify primary retrofit interventions on large stocks of buildings. Sustain. Cities Soc. 2019, 47, 101438. [CrossRef]

79. Battini, F.; Pernigotto, G.; Gasparella, A. Development of a shoeboxing approach for urban building energy modeling. In Proceedings of the 6th International High Performance Buildings Conference at Purdue, West Lafayette, IN, USA, 24-28 May 2021.

80. ASHRAE. ASHRAE Guideline 14-2014-Measurement of Energy, Demand, and Water Savings; ASHRAE: Atlanta, GA, USA, 2014.

81. Efficiency Valuation Organization (EVO). International Performance Measurement \& Verification Protocol-Core Concepts; EVO: Washington, DC, USA, 2016.

82. Prando, D.; Prada, A.; Ochs, F.; Gasparella, A.; Baratieri, M. Analysis of the energy and economic impact of cost-optimal buildings refurbishment on district heating systems. Sci. Technol. Built Environ. 2015, 21, 876-891. [CrossRef]

83. Ente Nazionale Italiano di Normazione (UNI). UNI/TS 11300-1-Energy Performance of Buildings Part 1: Evaluation of Energy need for Space Heating and Cooling; UNI: Milan, Italy, 2014.

84. European Committee for Standardization (CEN). EN 16798-1_Energy Performance of Buildings—Ventilation for Buildings—Part 1: Indoor Environmental Input Parameters for Design and Assessment of Energy Performance of Buildings Addressing Indoor Air Quality, Thermal Environment, Lighting and Acoustics-Module M1-6; CEN: Brussels, Belgium, 2019.

85. Haneef, F.; Battini, F.; Pernigotto, G.; Gasparella, A. A CitySim urban energy simulation for the development of retrofit scenarios for a neighborhood in Bolzano, Italy. In Proceedings of the Building Simulation Applications BSA 2019, Bolzano, Italy, 19-21 June 2019; Pernigotto, G., Patuzzi, F., Prada, A., Corrado, V., Gasparella, A., Eds.; Bozen-Bolzano University Press: Bolzano, Italy, 2020.

86. Battini, F.; Pernigotto, G.; Gasparella, A. Calibration of a UMI simulation model for a neighborhood in Bolzano, Italy. In Proceedings of the Building Simulation Applications BSA 2019, Bolzano, Italy, 19-21 June 2019; Pernigotto, G., Patuzzi, F., Prada, A., Corrado, V., Gasparella, A., Eds.; Bozen-Bolzano University Press: Bolzano, Italy, 2020. 
87. Kämpf, J.H.; Emmanuel, W. A verification of CitySim results using the BESTEST and monitored consumption values. In Proceedings of the Building Simulation Applications BSA 2015, Bolzano, Italy, 4-6 February 2015; Baratieri, M., Corrado, V., Gasparella, A., Patuzzi, F., Eds.; Bozen-Bolzano University Press: Bolzano, Italy, 2015.

88. Intergovernmental Panel on Climate Change (IPCC). Climate Change 2007: Synthesis Report. Contribution of Working Groups I, II and III to the Fourth Assessment Report of the Intergovernmental Panel on Climate Change; Core Writing Team, Pachauri, R.K., Reisinger, A., Eds.; IPCC: Geneva, Switzerland, 2008.

89. Organisation for Economic Co-operation and Development (OCED). The Economics of Climate Change Mitigation: Policies and Options for Global Action beyond 2012; OECD: Paris, France, 2012.

90. Italian Government. Decreto Interministeriale DM 26/06/2015-Applicazione delle metodologie di calcolo delle prestazioni energetiche e definizione delle prescrizioni e dei requisiti minimi degli edifici (Inter-Ministry Decree DM 26/06/2015-Application of the methodologies for the calculation of the building energy performance and for the definition of provisions and minimum requirements for buildings). GU 2015. Serie Generale n.162 del 15-07-2015-Suppl. Ordinario n. 39.

91. Ente Nazionale Italiano di Normazione (UNI). UNI 10351:2015-Materiali e Prodotti per Edilizia-Proprietà TermoigrometricheProcedura per la Scelta dei Valori di Progetto (UNI 10351:2015-Building Materials and Products-Thermophysical Propertiers—Procedure to Choose the Design Values); UNI: Milan, Italy, 2015.

92. Pernigotto, G.; Prada, A.; Cappelletti, F.; Gasparella, A. Impact of reference years on the outcome of multi-objective optimization for building energy refurbishment. Energies 2017, 10, 1925. [CrossRef]

93. Koordinationskonferenz der Bau- und Liegenschaftsorgane der Öffentlichen Bauherren (KBOB). Available online: https: / www. kbob.admin.ch (accessed on 18 August 2021).

94. Hoellinger, A.; Vasile, C.M.; Piccon, L. Embodied energy of windows in buildings: Impact of architectural and technical choices-Part 1. Int. J. Environ. Sci. 2017, 2, 177-183.

95. European Commission. Commission Delegated Regulation (EU) No 244/2012 of 16 January 2012. OJEU 2012, L 81, 18-36.

96. President of the Italian Republic. Decreto del Presidente della Repubblica Italiana No 633/1972-Istituzione e disciplina dell'imposta Sul Valore Aggiunto (Decree of the President of the Italian Republic nr. 633/1972-Establishment and Regulation of the added Value tax). GU 1972. Serie Generale n.292 del 11-11-1972-Suppl. Ordinario n. 1.

97. Autonomous Province of Bolzano/Südtirol. 2020. DGP 235/2020-Prestazione Energetica Nell'edilizia e Bonus Energia in Attuazione delle Direttive Europee (UE) 2018/844, 2009/28/CE, 2010/31UE e 2012/27/UE (DGP 235/2020—Building Energy Performance and Energy Bonus in the Framework of the Adoption of the European Directives 2018/844, 2009/28/CE, 2010/31UE e 2012/27/UE). Available online: https:/ / www.provincia.bz.it/aprov/giunta-provinciale/delibere.asp (accessed on 18 August 2021).

98. Kämpf, J.H.; Robinson, D. A hybrid CMA-ES and HDE optimisation algorithm with application to solar energy potential. Appl. Soft. Comput. 2009, 9, 738-745. [CrossRef]

99. Kämpf, J.H.; Wetter, M.; Robinson, D. A comparison of global optimization algorithms with standard benchmark functions and real-world applications using EnergyPlus. J. Build. Perform. Simu. 2010, 3, 103-120. [CrossRef]

100. Passive House Institute-Component Database. Available online: https://database.passivehouse.com/en/components/list/ ventilation_small (accessed on 18 August 2021). 